Utah State University

DigitalCommons@USU

\title{
Correlation of Age-Specific Phenylalanine Levels on Intellectual Outcome in Patients with Phenylketonuria
}

Krista S. Viau

Utah State University

Follow this and additional works at: https://digitalcommons.usu.edu/etd

Part of the Public Health Commons

\section{Recommended Citation}

Viau, Krista S., "Correlation of Age-Specific Phenylalanine Levels on Intellectual Outcome in Patients with Phenylketonuria" (2010). All Graduate Theses and Dissertations. 739.

https://digitalcommons.usu.edu/etd/739

This Thesis is brought to you for free and open access by the Graduate Studies at DigitalCommons@USU. It has been accepted for inclusion in All Graduate Theses and Dissertations by an authorized administrator of DigitalCommons@USU.For more information, please contact digitalcommons@usu.edu.

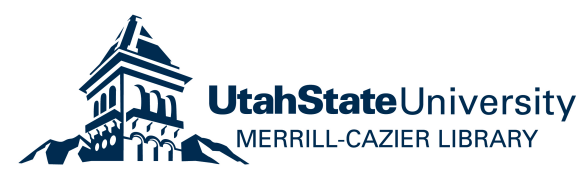


CORRELATION OF AGE-SPECIFIC PHENYLALANINE LEVELS ON

INTELLECTUAL OUTCOME IN PATIENTS WITH PHENYLKETONURIA

by

Krista S. Viau

A thesis submitted in partial fulfillment

of the requirements for the degree

of

MASTER OF SCIENCE

in

Nutrition and Food Sciences

Approved:

Heidi Wengreen, RD, PhD

Major Professor

Joan Hevel, $\mathrm{PhD}$

Committee Member
Korry Hintze, PhD

Committee Member

Byron Burnham, Ed.D

Dean of Graduate Studies

UTAH STATE UNIVERSITY

Logan, Utah 
Copyright (C) Krista Viau 2010

All Rights Reserved 


\section{ABSTRACT}

Correlation of Age-Specific Phenylalanine Levels on Intellectual Outcome in Patients with Phenylketonuria

by

\section{Krista S. Viau, Master of Science}

Utah State University, 2010

Major Professor: Dr. Heidi Wengreen

Department: Nutrition, Dietetics, and Food Sciences

This study includes data collected from a retrospective chart review of patients with phenylketonuria treated at the University of Utah Metabolic Clinic. Among the approximately 175 patients treated for phenylketonuria at this clinic, 55 patients $(28$ female) met the inclusion criteria for the present study. Based on the diagnostic Phe level, $66.7 \%$ were classified as having classic phenylketonuria, $18.5 \%$ with moderate phenylketonuria, and $14.8 \%$ with mild phenylketonuria.

Subjects' cognitive status was measured with one of three neuropsychological tests: Wechsler Intelligence Scale for Children third and fourth editions and the Wechsler Adult Intelligence Scale third edition. Due to structural differences among the tests, only the Verbal Comprehension Index, Block Design subtest, and Symbol Search subtest were compiled and included for statistical analysis.

Quality of metabolic control was assessed with blood and plasma phenylalanine levels throughout each patient's life. Three developmental age periods were defined (0-5 
years, 6-10 years, and $>10$ years). The index of dietary control (IDC), defined as mean of median phenylalanine levels for each patient in 12-month intervals, was calculated for each developmental period. The mean standard deviation (SD) of blood phenylalanine levels and mean number of blood phenylalanine samples were also assessed in 12-month intervals.

Linear regression analysis was used to evaluate the most recent measures of intelligence in relationship to IDC and mean SD blood phenylalanine levels during developmental periods. Logistic regression was also used to examine the association between mean number of phenylalanine samples during each developmental period and the likelihood of maintaining blood phenylalanine less than $360 \mu \mathrm{mol} / \mathrm{L}$ and within one SD of the IDC.

Using multivariate linear regression, a model including IDC and number of samples from lifetime, 0-5 years, and 6-10 years were significantly associated with perceptual reasoning, but IDC regression coefficients were not significantly correlated. Multivariate logistic regression revealed a 32 percent decrease in risk of IDC exceeding the upper limit of the treatment range for each additional phenylalanine assessment per year between the ages of $6-10$ years $(p=0.001)$. No association was observed between SD blood phenylalanine and cognitive outcomes or frequency of sampling during any developmental periods. 


\section{ACKNOWLEDGMENTS}

I would especially like to thank my advisor, Dr. Heidi Wengreen, for her excellent editing, advising, and assistance. This thesis would not have been possible without her willingness to help any issue that arose throughout the entire process. I am also greatly appreciative of my committee members, Dr. Korry Hintze and Dr. Joanie Hevel.

I owe my deepest gratitude to my supervisors and coauthors, Dr. Nicola Longo and Sharon Ernst, whose encouragement, guidance, and support enabled me to develop an in-depth understanding of the material and complete this thesis. Lastly, I offer my

regards to all coauthors, including Dr. Nancy Cantor and Dr. Larissa Furtado (appendix).

Krista S. Viau 
CONTENTS

Page

ABSTRACT.

iii

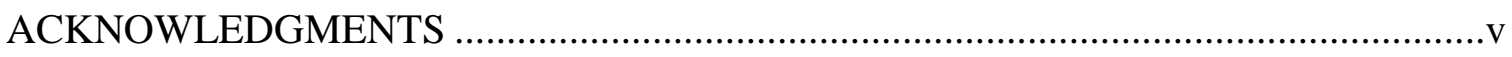

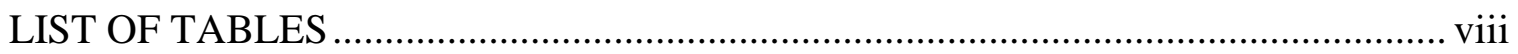

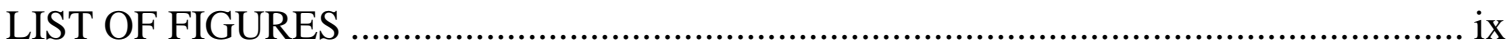

CHAPTER

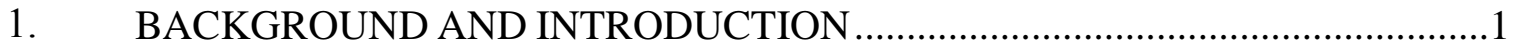

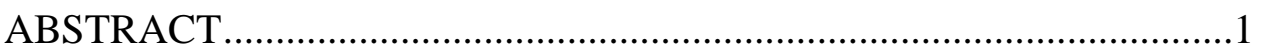

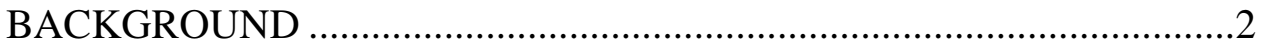

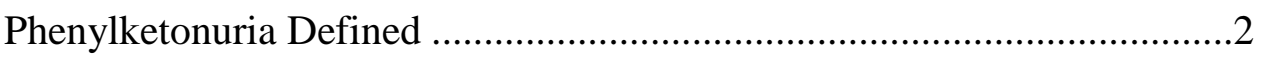

Expanded Newborn Screening and Diagnosis of PKU................................. 3

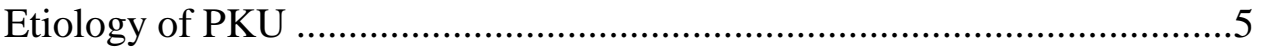

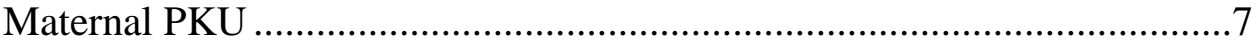

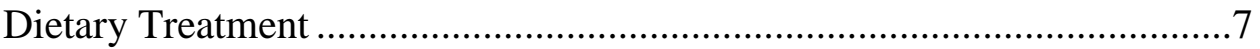

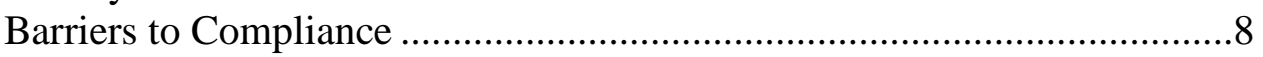

Prognosis for Early Treated Patients...........................................................

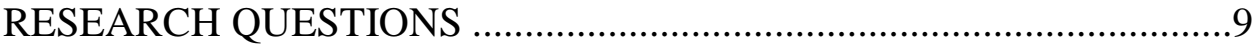

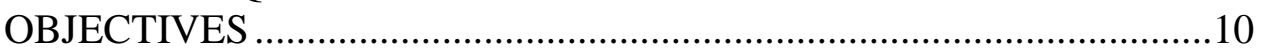

UNIVERSITY OF UTAH METABOLIC CLINIC..................................10

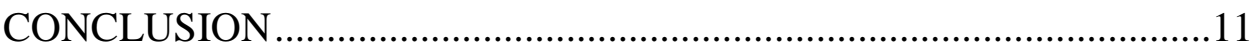

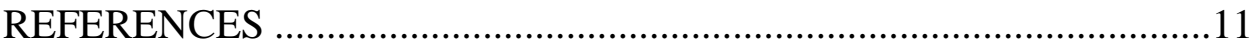

2. LITERATURE REVIEW OF THE CONSEQUENCES, PATHOPHYSIOLOGY, AND TREATMENT OF PHENYLKETONURIA ……........................................14

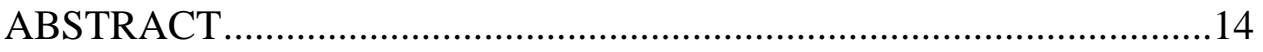

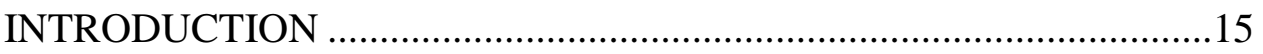

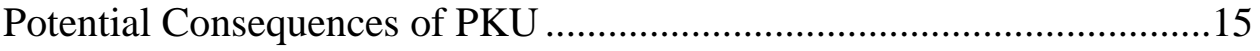

Executive Functioning Deficits......................................................15

Intelligence and Academic Achievement .......................................17

Processing Speed ……………………………………….......18

Late Treated PKU ………………………………………….....20

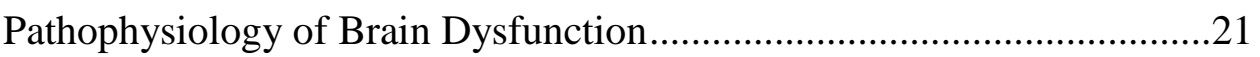

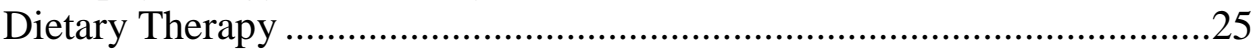

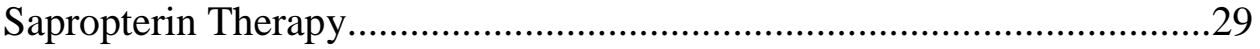


Enzyme Replacement Therapy $\ldots . . . \ldots \ldots \ldots \ldots$

Enzyme Replacement Therapy ...........................................................30

Treatment with Large Neutral Amino Acids ...........................................30

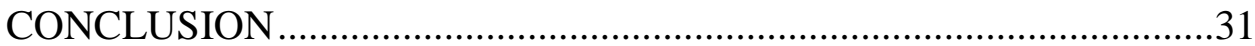

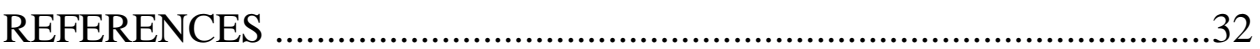

3. CORRELATION OF AGE-SPECIFIC PHENYLALANINE LEVELS ON INTELLECTUAL OUTCOME IN PATIENTS WITH PHENYLKETONURIA .37

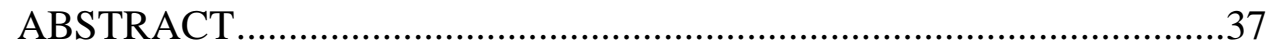

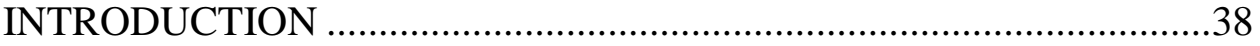

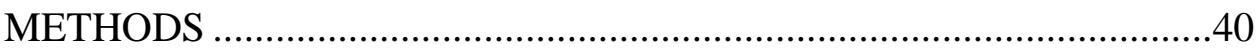

Subjects .........................................................................................40

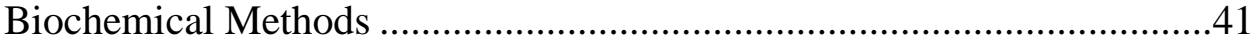

Neuropsychological Assessment ......................................................42

Statistical Analysis ........................................................................44

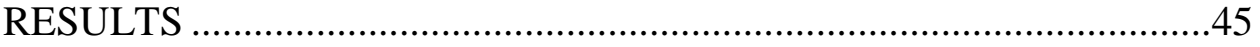

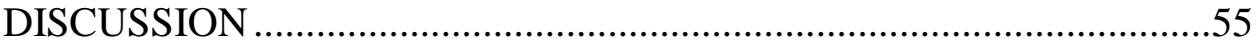

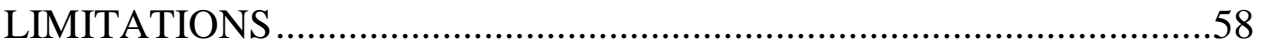

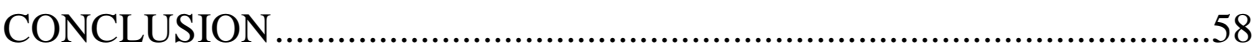

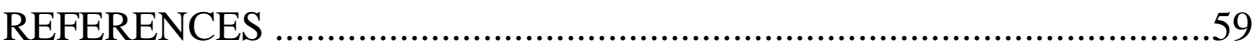

4. CONCLUSIONS AND FUTURE DIRECTIONS ...........................................64

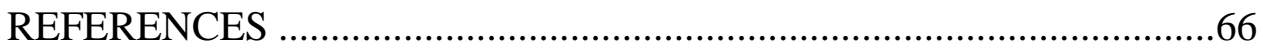

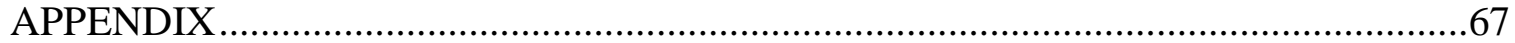




\section{LIST OF TABLES}

Table

3-1 Description of sample demographic and treatment variables

3-2 Distribution of demographic and treatment variables.

3-3 Pearson product moment correlations between neuropsychological tests and treatment variables

3-4 Multivariate Regression: association between Index of Dietary Control and standard deviation of blood Phe and measures of intelligence

3-5 Logistic Regression: number of blood Phe samples predicting the likelihood of maintaining blood Phe within treatment range of $(120-360 \mu \mathrm{mol} / \mathrm{L})$ and stability of Phe within one standard deviation per age group 


\section{LIST OF FIGURES}

Figure

1-1 Phenylalanine metabolism

3-1 Index of Dietary Control, defined as the mean 12-month median of Phe levels, for all patients per year of life (raw data).

3-2 Bivariate regression analysis: association between Verbal Comprehension Index (VCI) scores and Index of Dietary Control, defined as the mean 12-month median of Phe levels for each patient during the specified time frame

3-3 Bivariate regression analysis: association between Verbal Comprehension Index (VCI) scores (excluding the Wechsler Adult Intelligence Scale scores) and Index of Dietary Control, defined as the mean 12-month median of Phe levels for each patient during the specified time frame

3-4 Bivariate regression analysis: association between Block Design Subtest scores measuring perceptual reasoning skills and Index of Dietary Control, defined as the mean 12-month median of Phe levels for each patient during the specified time frame

3-5 Bivariate regression analysis: association between Symbol Search Subtest scores measuring processing speed and Index of Dietary Control, defined as the mean 12-month median of Phe levels for each patient during the specified time frame 


\title{
CHAPTER 1
}

\section{BACKGROUND AND INTRODUCTION}

\begin{abstract}
Phenylketonuria (PKU) is an inherited disorder of protein metabolism impairing the body's ability to metabolize the essential amino acid phenylalanine (Phe). It is caused by a defect in the gene encoding phenylalanine hydroxylase $(\mathrm{PAH})$ or defective synthesis/recycling of the cofactor tetrahydrobiopterin $\left(\mathrm{BH}_{4}\right)$. PKU is generally diagnosed at birth through the Newborn Screening Program to facilitate prompt treatment. If left untreated, it will result in severely impaired cognitive development. In addition, pregnancy in women with PKU is challenging as elevated blood Phe is extremely teratogenic. The primary treatment for PKU is strict control of dietary Phe intake to the minimum amount needed to support growth and protein turnover. Patients with PKU are advised to maintain this diet throughout life for optimal outcomes, but adherence to the diet is arduous. Despite adequate treatment, patients with PKU may demonstrate mild intellectual deficits in arithmetic, reading, basic spelling, and perceptual skill that worsen over time. Multiple studies also revealed a significant negative relationship between blood Phe concentration and intelligence quotient (IQ). The primary objective of this study is to determine if there are certain developmental periods in which phenylalanine levels have a greater impact on most recent measures of intelligence. It will also examine the relationship between frequency of testing blood Phe via filter paper cards and maintenance of Phe levels within the treatment range of 120 to $360 \mu \mathrm{mol} / \mathrm{L}$.
\end{abstract}




\section{BACKGROUND}

\section{Phenylketonuria Defined}

Phenylketonuria (PKU) is an autosomal recessive disorder of protein metabolism, which inhibits the body's ability to metabolize the essential amino acid phenylalanine (Phe). Due to the deficiency or lack of the hepatic enzyme phenylalanine hydroxylase (PAH) or its cofactor tetrahydrobiopterin $\left(\mathrm{BH}_{4}\right)$, phenylalanine cannot be converted to the amino acid tyrosine (Tyr). This results in the accumulation of Phe and a deficiency of Tyr, a precursor to the neurotransmitters dopamine and norepinephrine in the central nervous system (Waisbren et al. 2007).

PKU results in irreversible and progressive brain damage if left untreated. Elevated Phe interferes with myelination, synaptic sprouting, and dendritic pruning of cerebral tissue (Schulze et al. 2009). The brain is the most susceptible to the neurotoxic effects of elevated Phe during the first years of life (Feldmann et al. 2005). When PKU is diagnosed during the neonatal period by newborn screening and managed by life-long nutrition support, mental retardation and major neurological complications, including seizures and spasticity, are prevented (Weglage et al. 1997).

PKU is the most common inborn error of metabolism. The highest rates of PKU are seen in Ireland (1:4500) and Eastern Europe (Estonia: 1:6000, Hungary 1:9000, and Latvia 1:8700). Incidence in North America is approximately 1:10,000 live births (Waisbren et al. 2007). PKU is classified into three categories based on severity at diagnosis: classic PKU (plasma Phe $>1200 \mu \mathrm{mol} / \mathrm{L}$ ), moderate PKU (plasma Phe $600-1200 \mu \mathrm{mol} / \mathrm{L}$ ), or mild PKU

(plasma Phe 120-600 $\mu \mathrm{mol} / \mathrm{L}$ ) (Waisbren et al. 2007). Approximately 50 percent of detected cases are classical PKU, 30 percent are moderate PKU, and 20 percent are mild (Schulze et 
al. 2009). Only two percent of individuals with hyperphenylalanemia have a defect in $\mathrm{BH}_{4}$ synthesis or recycling rather than a mutation in the PAH gene (Williams et al. 2008).

The inability to synthesize or regenerate the $\mathrm{PAH}$ cofactor $\mathrm{BH}_{4}$ results in one of five different genetic conditions that mimic PKU with elevated phenylalanine levels. These conditions were differentiated from PKU in the 1970s after it became clear that a portion of patients with hyperphenylalanemia experienced neurological damage despite early treatment. Administration of synthetic $\mathrm{BH}_{4}$ rapidly normalizes plasma Phe levels without use of a Phe-restricted diet (Longo 2009).

\section{Expanded Newborn Screening and Diagnosis of PKU}

The advent of newborn screening came about with the work of Asbjorn Folling in Norway nearly 70 years ago (Brin et al. 2006). It was developed to identify disorders of amino acid metabolism, which were not typically diagnosed until developmental delay or other neurological symptoms became apparent (Schulze et al. 2009). State newborn screening programs in the United States began approximately 40 years ago for PKU with the filter paper-based testing technology developed by Robert Guthrie (Brin et al. 2006; Longo 2009). This method involves placing capillary blood from a heel prick on an Agar plate containing Bacillus subtilis, which requires Phe to grow. A Phe analog that inhibits bacterial growth is also applied. High levels of phenylalanine counteract the inhibitor and permit bacterial growth (Guthrie and Susi 1963; Schulze et al. 2009). This method allows mass screening for PKU, as it is simple, inexpensive, reproducible, and accurate (Blumenfeld et al. 1966).

Tandem mass spectrometry (MS/MS) was introduced to the newborn screening 
program in the late 1990s. MS/MS can simultaneously perform amino acid and acylcarnitine analyses on the same blood sample, thus drastically increasing the number of disorders included in the screening (Schulze et al. 2009). In order for a disease to be included in the newborn screen, it must meet the following qualifications:

1. Condition is identifiable in a presymptomatic or early stage of the disease.

2. A test with the appropriate specificity and sensitivity is available for large populations.

3. The benefits of early intervention were demonstrated (Schulze et al. 2009). In January of 2006, the Utah Department of Health expanded its newborn screening program from 4 disorders to 36 disorders, including diseases of amino acid, fatty acid, and organic acid metabolism. The screening is done via blood sample collected between 48 hours and 5 days after birth (Utah Administrative Code 2009). The second specimen is collected between 7 to 28 days of age. According to Title 26 of the Utah Health Code, all infants are tested, "except in the case where parents object on the grounds that they are members of a specified, well-recognized religious organization whose teachings are contrary to the tests required" (Utah Code 1998).

In addition to newborn screening in those infants who screen positive for PKU, a urinary pterin test and dihydropterindine reductase (DHPR) blood spot test are customary to differentiate between $\mathrm{PKU}$ and a disorder of $\mathrm{BH}_{4}$ synthesis or recycling, as the treatment differs (Schulze et al. 2009). 


\section{Etiology of PKU}

PKU is characterized by a defect in the gene encoding the enzyme phenylalanine hydroxylase (PAH) located on chromosome 12q22-24.1. Over 500 mutations in the PAH gene have been identified and most patients have two different mutations (compound heterozygotes) (Santos et al. 2010). This defect inhibits the stereospecific hydroxylation of Phe, the committed step in the metabolism of this essential amino acid (Waisbren et al. 2007; Williams et al. 2008). The hydroxylation of Phe to Tyr requires PAH, the cofactor $\mathrm{BH}_{4}$, molecular oxygen, and the enzymes responsible for regenerating $\mathrm{BH}_{4}$. While this system is required for the conversion of Phe to Tyr, it is not needed for decarboxylation or transamination reactions (see Figure 1-1). These alternate pathways produce the Phe metabolites phenylpyruvate, phenylacetylglutamate, phenyl-lactate, and $o$ hydroxyphenylacetate (Williams et al. 2008).

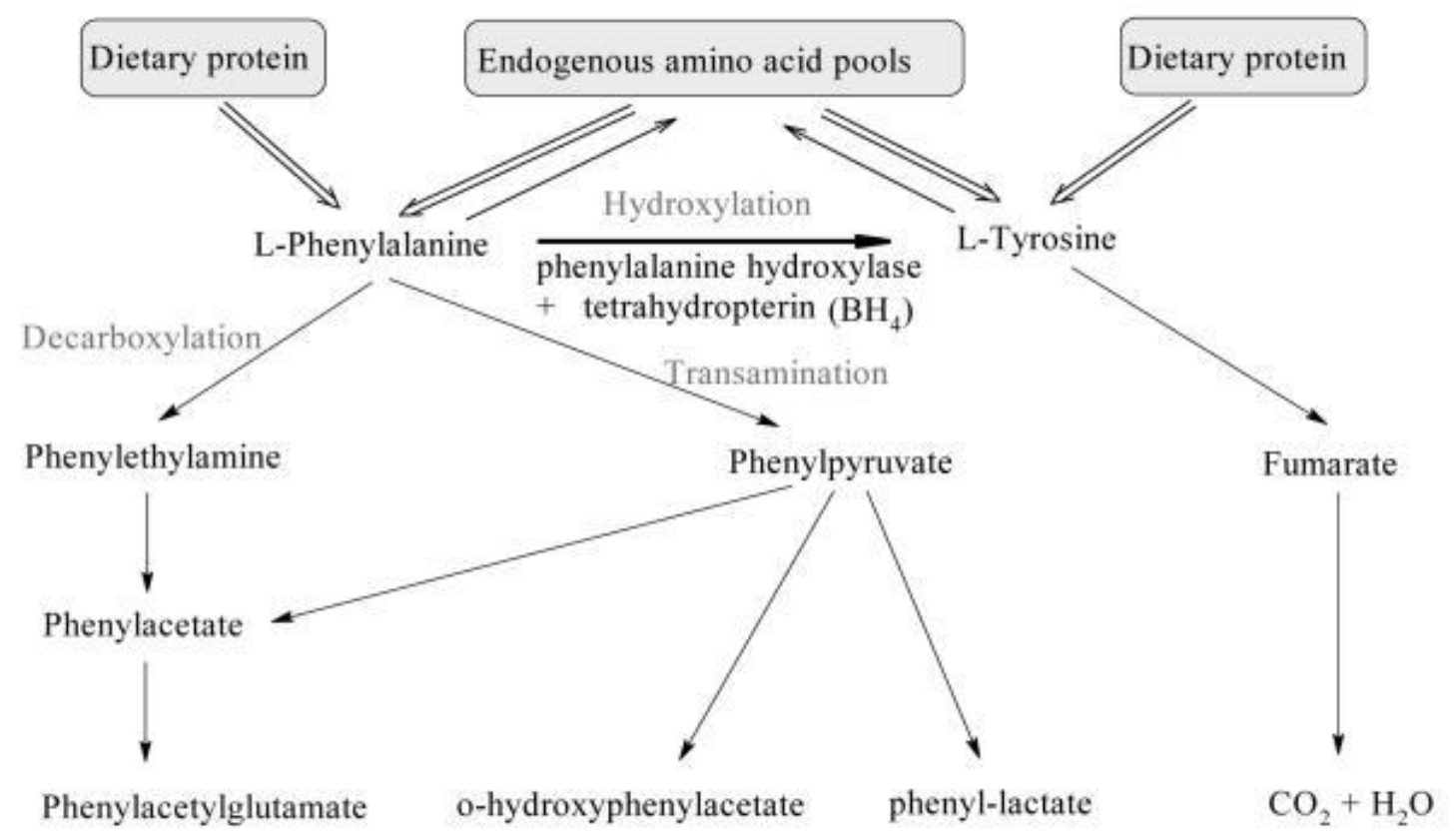

Figure 1-1 Phenylalanine metabolism (Williams et al. 2008) 
Hyperphenylalanemia caused by a defect in $\mathrm{BH}_{4}$ synthesis/recycling can result from mutations in the gene encoding 6-pyruvoyl-tetrahydrobiopterin synthase (PTPS) (60\%), DHPR (30\%), GTP cyclohydrolase I (5\%) and pterin-4a-carbinolamine dehydratase (PCD) (5\%). The biosynthesis of $\mathrm{BH}_{4}$ in humans involves the catalyst GTP cyclohydrolase I, which is required for the rate-limiting reaction. The enzyme activity is regulated by GTP cyclohydrolase I feedback regulatory protein (GFRP) where it is stimulated in the presence of increased Phe levels and inhibited with excess $\mathrm{BH}_{4}$. PTPS converts 7,8-dihydroneopterin triphosphate to 6-pyruvoyl-tetrahydrobiopterin.

Sepiapterin reductase (SR) then catalyzes the two-step reaction to complete the synthesis of $\mathrm{BH}_{4}$. Tetrahydrobiopterin donates electrons during the hydroxylation of Phe, Tyr, and tryptophan. Lastly, the two enzymes PCD and DHPR are required to regenerate $\mathrm{BH}_{4}$ from its oxidized form (Longo 2009).

Phe homeostasis is regulated by dynamic input and runout flux. The primary sources of Phe are dietary intake and endogenous regeneration of amino acid stores (Williams et al. 2008). Utilization of Phe occurs when Phe is used to make proteins or converted to Tyr or other metabolites. If the runout flux is continually disordered as it is in PKU, the steady state concentrations will eventually change, resulting in an accumulation of Phe and Phe metabolites (Williams et al. 2008).

The phenotypic outcome of PKU is multifactorial in origin as there are numerous factors that influence the flux of Phe in humans, including variations in intestinal absorption, hepatic uptake of dietary Phe, rate of protein synthesis, and influx of Phe across the blood brain barrier (BBB) (Santos et al. 2010). Due to the heterogeneity in the 
PAH enzyme locus and individual differences, the phenotype-genotype correlation varies considerably.

\section{Maternal PKU}

Elevated blood phenylalanine concentrations are teratogenic to the offspring of women with PKU (Williams et al. 2008; Maillot et al. 2008). Specifically, high Phe can lead to an increased rate of miscarriage, facial dysmorphism, mental retardation, microcephaly, congenital heart disease, and intrauterine growth failure (Acosta and Yannicelli 2001; Williams et al. 2008). Many of the birth defects associated with maternal PKU syndrome are preventable with appropriate control of Phe concentrations prior to conception and during pregnancy (Maillot et al. 2008). Fetal exposure to maternal Phe levels is exacerbated by the transplacental gradient for Phe, which produces ratios of 1:1.5 and up to 1:2.9 early in pregnancy (Williams et al. 2008). Therefore, frequent monitoring and stringent control of phenylalanine levels are crucial during pregnancy. Weekly Phe levels are recommended with a goal of Phe concentrations between 100 to $250 \mu \mathrm{mol} / \mathrm{L}$. Stability of Phe concentrations are also of importance, as negative outcomes were observed in those with a large standard deviation even with mean Phe concentrations within the treatment range (Maillot et al. 2008).

\section{Dietary Treatment}

The primary treatment for PKU is strict control of dietary Phe intake. If one only consumed natural protein foods, the degree of protein restriction necessary to reduce plasma Phe concentrations to treatment levels would lead to marked protein malnutrition, failure-to-thrive, and death. Therefore, individuals with PKU must also supplement their 
diet with a phenylalanine-free medical formula that provides tyrosine and other amino acids. Medical foods meet approximately 85 to 90 percent of the individual's protein needs (Przyrembel and Bremer 2000; Acosta and Yannicelli 2001). The University of Utah Metabolic Clinic advises its patients with PKU to continue this diet throughout life for optimal outcomes. The clinicians recommend maintaining Phe levels between 120 and $360 \mu \mathrm{mol} / \mathrm{L}$.

\section{Barriers to Compliance}

Adherence to the prescribed diet for PKU is difficult and time-consuming. Barriers include: the restrictive and often unpalatable diet, expense of medical food and low protein food, difficulty taking prescribed medical foods at school or work, frequency of testing, psychosocial issues, lack of health insurance, complicated diet planning, and misunderstanding of the diet (Bilginsoy et al. 2005; Bik-Multanowski et al. 2009).

Qualitative interviews were conducted in New Zealand with 8 early-treated adults concerning their experiences living with PKU. Most participants reported a "difference" between oneself and peers in relation to eating patterns, often leading to lack of social acceptance and exclusion. On the other hand, refusal of food also provoked anxiety, as food is a common symbol of community and relationship. Participants described a greater inclination to eat outside their diet prescription if the comfort and feelings of others were at stake. Lastly, participants explained the difficulty coping with modern responsibilities without the use of convenient food options (Frank et al. 2007). 


\section{Prognosis for Early Treated Patients}

Early therapy prevents mental retardation in patients with PKU; however, several studies revealed intellectual deficits in patients with early and continuously treated PKU (Weglage et al. 1997). Despite adequate treatment, PKU patients tend to demonstrate mild deficits in arithmetic, reading comprehension, basic spelling and perceptual skill that worsen over time (Chang et al. 2000). It has also been demonstrated that patients with Phe levels above $400 \mu \mathrm{mol} / \mathrm{L}$ at time of testing perform poorly on executive function tests (Stemerdink et al. 2000).

A significant negative association between Phe concentration and intelligence quotient (IQ) was documented in a meta analysis (Waisbren et al. 2007). Regression analyses showed a decrease in IQ of 1.3 to 3.9 points for every $100 \mu \mathrm{mol} / \mathrm{L}$ increase in lifetime plasma Phe in early treated patients. Concurrent Phe levels (phenylalanine levels at the time testing was performed) reduced the measured IQ by 0.5 to 1.4 points for every $100 \mu \mathrm{mol} / \mathrm{L}$ increase in plasma Phe (Waisbren et al. 2007). The stability of Phe concentrations may also impact IQ. Anastasoaie et al. (2008) discovered a correlation between the standard deviation of plasma Phe levels and the most recent measure of IQ. Mean plasma Phe and mean standard deviation of plasma Phe achieved a statistically significant positive correlation $(\mathrm{r}=0.51, \mathrm{p}=0.004)$, indicating that those with higher plasma Phe experienced more instability in Phe levels (Anastasoaie et al. 2008).

\section{RESEARCH QUESTIONS}

1. Are there certain developmental periods in which adequate control of plasma Phe has a stronger influence on measures of intelligence? 
2. Does frequency of blood levels positively correlate with the stability and maintenance of plasma Phe within the treatment range?

\section{OBJECTIVES}

1. Objective 1: Analyze the index of dietary control (mean 12-month median Phe levels) and mean standard deviation of Phe levels submitted via filter paper cards and blood draws and analyzed by MS/MS during specific developmental periods (0-5 years, 6-10 years, and $>10$ years) and compare them to the most recent measures of IQ.

2. Objective 2: Examine the correlation between frequency of testing via filter paper and plasma amino acids and maintenance of Phe levels within the treatment range of 120 to $360 \mu \mathrm{mol} / \mathrm{L}$ and within one standard deviation of the index of dietary control.

\section{UNIVERSITY OF UTAH METABOLIC CLINIC}

Adherence to dietary recommendations and recommended frequency of blood Phe testing tends to decline after early childhood in patients followed by the University of Utah Metabolic Clinic. This is of particular concern as brain development continues into adolescence, thus increasing the risk for cognitive deficits later in life. Defining the importance of metabolic control during specific developmental periods may improve adherence to dietary treatment. In addition, demonstrating a link between frequency of testing and metabolic control may encourage patients to send blood Phe samples as per clinic recommendations. 


\section{CONCLUSION}

While the most deleterious effects of PKU can be prevented with prompt and continuous dietary therapy, mild deficits in intelligence, academic achievement, and executive function skills may still occur with appropriate treatment. The current recommendation in the United States is to continue a Phe-restricted diet for life. However, adherence to diet prescription typically begins to wane after early childhood. This study aims to investigate the impact of appropriate control on neuropsychological assessments during certain developmental periods to determine if there is a period where strict dietary control is more pertinent than others. Evaluation of the association between frequency of blood levels and control of Phe will help determine the next step in improving self-monitoring.

\section{REFERENCES}

Acosta PB, Yannicelli S (2001) Nutrition Support Protocols, $4^{\text {th }}$ ed. Columbus, Ohio: Ross Products Division, Abbott Laboratories.

Anastasoaie V, Kurzius L, Forbes P, Waisbren S (2008) Stability of blood phenylalanine levels and IQ in children with phenylketonuria. Mol Genet Metab 95: 17-20.

Bik-Multanowski M, Didycz B, Mozrzymas R, Nowacka M, Kaluzny L, Cichy W, Schneiberg B, Amilkiewicz J, Bilar A, Giezwska M, Lange A, Starostecka E, Chrobot A, Wojcicja-Bartlomiejczyk BI, Milanowski A (2008) Quality of life in noncompliant adults with phenylketonuria after resumption of the diet. J Inherit Metab Dis doi:10.1007/s10545-008-0978-7.

Bilginsoy C, Waitzman N, Leonard CO, Ernst SL (2005) Living with Phenylketonuria: perspectives of patients and their families. J Inderit Metab Dis 28: 639-649.

Blumenfeld CM, Wallace MJ, Anderson R (1966) Phenylketonuria - The Guthrie Screening Test: a method of quantitation, observations of reliability and suggestions for improvement. California Medicine 105: 429-434. 
Brin A, Johnson K, McPherson M, Lloyd-Puryear MA, Tonniges T, van Dyck PC, Mann MY (2006) Recommendations: how far have we come? American Academy of Pediatrics Newborn Screening Task Force. Pediatrics 117: S194-S211.

Chang P-N, Gray RM, O'Brien L (2000) Patterns of academic achievements among patients treated early with phenylketonuria. Eur J Pediatr 159: [Suppl 2]:S96-S99.

Feldmann R, Denecke J, Grenzebach M, Weglage J (2005) Frontal lobe-dependent functions in treated phenylketonuria: blood phenylalanine concentrations and long-term deficits in adolescents and young adults. J Inherit Metab Dis 28: 445-455.

Frank N, Fitzgerald R, Legge M (2007) Phenylketonuria - the lived experience. NZMJ 120: 2728.

Guthrie R, Susi A (1963) A simple phenylalanine method for detecting phenylketonuria in large populations of newborn infants. Pediatrics 32: 318-343.

Longo N (2009) Disorders of biopterin metabolism. J Inherit Metab Dis 32: 333-342.

Maillot F, Lilburn M, Baudin J, Morley DW, Lee PJ (2008) Factors influencing outcomes in the offspring of mothers with phenylketonuria during pregnancy: the importance of variation in maternal blood phenylalanine. Am J Clin Nutr 88: 700-705.

Przyrembel H, Bremer HJ (2000) Nutrition, physical growth, and bone density in treated phenylketonuria. Eur J Pediatr 159: S129-S135.

Santos LL, Fonseca CG, Starling AL, Januário JN, Aguiar MJ, Peixoto MG, Carvalho MR (2010) Variations in genotype-phenotype correlations in phenylketonuria patients. Genet Mol Res 9: 1-8.

Schulze A, Matern D, Hoffmann GF (2009) Newborn screening. In: Sarafoglou K, Hoffman GF, Roth KS, eds. Pediatric Endocrinology and Inborn Errors of Metabolism. New York: McGraw Hill Companies, pp 17-36.

Stemerdink BA, Kalverboer AF, Van der Meere JJ, Van der Molen MW, Huisman J, De Jong WA, Slijper FME, Verkerk PH, Van Spronsen FJ (2000) Behavior and school achievement in patients with early and continuously treated phenylketonuria. J Inherit Metab Dis 23: 548-562.

Utah Administrative Code: Rule R398-1. Newborn Screening. 2009. Available at: http://www.rules.utah.gov/publicat/code/r398/r398-001.htm. Accessed September 11, 2009.

Utah Code: 26-10-6 Testing of Newborn Infants. Utah Legislature. 1998. Available at: http://www.le.utah.gov/UtahCode/getCodeSection?code=26-10-6. Accessed September 11, 2009. 
Waisbren S, Noel K, Fahrbach K et al (2007) Phenylalanine blood levels and clinical outcomes in phenylketonuria: a systematic literature review and meta-analysis. Mol Genet Metab 92: 63-70.

Weglage J, Ullrich K, Pietsch M, Funders B, Guttler F, Harms E (1997) Intellectual, neurologic, and neuropsychologic outcome in untreated subjects with nonphenylketonuria hyperphenylalaninemia. Pediatric Res 42: 378-384.

Williams RA, Mamotte CD, Burnett JR (2008) Phenylketonuria: an inborn error of metabolism. Clin Biochem Rev 29: 31-40. with permission of the Australian Association of Clinical Biochemists. 


\title{
CHAPTER 2
}

\section{LITERATURE REVIEW OF THE CONSEQUENCES, PATHOPHYSIOLOGY AND TREATMENT OF PHENYLKETONURIA}

\begin{abstract}
Phenylketonuria (PKU) is an autosomal recessive disorder of protein metabolism with devastating neurological consequences. If left untreated it causes profound mental retardation, microcephaly, and behavior disturbances. Early treatment in the neonatal period with a phenylalanine (Phe)-restricted diet prevents brain damage. However, early treated patients often exhibit mild deficits in executive and intellectual functioning, specifically, attention, processing speed, language, perception and visual spatial abilities. These impairments are attributed to defects in myelination, white matter abnormalities, and dopamine depletion in the prefrontal cortex. The brain is most vulnerable to elevated Phe during development, which continues from early embryogenesis through adolescence. Therefore, clinicians promote continuing a Phe-restricted diet throughout life to achieve optimal outcomes. The diet consists of Phe-free amino acid modules and measured amounts of natural protein to maintain blood Phe levels within a therapeutic range. However, there is no consensus on the appropriate blood Phe concentrations for this population. Additional treatment options for PKU are available, such as sapropterin dihydrochloride (pharmacological equivalent of tetrahydrobiopterin), enzyme replacement therapy, and large neutral amino acids.
\end{abstract}


INTRODUCTION

Phenylketonuria (PKU) is an inherited disorder of protein metabolism, which inhibits the body's ability to metabolize the essential amino acid phenylalanine (Phe) (Burgard et al. 2009). It is caused by a defect in the enzyme phenylalanine hydroxylase (PAH) or by defective synthesis/recycling of its co-factor tetrahydrobiopterin $\left(\mathrm{BH}_{4}\right)$. Up to 90 percent of phenylalanine intake is normally metabolized into tyrosine (Tyr), the amino acid precursor to dopamine and norepinephrine (van Spronsen and Enns 2010). PKU impairs the conversion of Phe to Tyr leading to an accumulation of Phe, which is neurotoxic (Burgard et al. 2009). Many treatment centers recommend maintaining blood Phe concentrations between 120 to $360 \mu \mathrm{mol} / \mathrm{L}$ for optimal outcomes.

\section{Potential Consequences of PKU}

Untreated PKU causes severe neurological damage, especially to developing white matter. Symptoms may include profound mental retardation, microcephaly, delayed speech, seizures and behavior abnormalities (Sharman et al. 2009). However, even with early and continuous treatment, patients with PKU exhibit mild deficits in executive and intellectual functioning, including processing speed, motor skills, perception and visual spatial abilities, and language (Gassio et al. 2005; Janzen and Nguyen 2010).

\section{Executive Functioning Deficits}

Executive functioning is characterized by the ability to plan and organize, use working memory, control impulsivity, switch tasks, maintain sustained attention, and integrate information across space and time (Williams et al. 2008; Sharman et al. 2009). 
Appropriate executive functioning is dependent on two areas of the prefrontal cortex in the brain: the dorsolateral prefrontal cortex and the orbitomedial prefrontal cortex. Insults to the dorsolateral region are related to cognitive impairments and those to the orbitofrontal region result in behavioral disturbances (Antshel and Waisbren 2003).

Attention is one of the most prominent executive functioning skills. A welldeveloped executive system is required in order to initiate, sustain, and direct attention (Antshel and Waisbren 2003). Similarities in brain function between attention deficit hyperactivity disorder (ADHD) and PKU may contribute to the concentration difficulties seen in PKU. Among 38 children with PKU, 50 percent of parents reported attention deficit symptoms in their children and 26 percent used a stimulant medication for these symptoms. Stimulant use was remarkably higher than that for the general population (5 percent) and compared to a control population with type 1 diabetes ( 6.5 percent $)$, as this population also has a chronic metabolic disease. ADHD is believed to be associated with decreased levels of dopamine and norepinephrine and with executive functioning deficits (Arnold et al. 2004). The onset of ADHD symptoms in PKU may be attributed to a gene called MAO-B, which can increase concentrations of the toxic Phe metabolite phenylethylamine (Feillet et al. 2010).

A case-control study (Leuzzi et al. 2004) demonstrated that PKU patients had impaired performance on executive functions tests compared to age-matched controls. PKU patients exhibited mild deficits in planning and sustained attention. Those with Phe levels over $400 \mu \mathrm{mol} / \mathrm{L}$ (mean of median Phe levels from birth to 4 years and 6 months before and after neuropsychological assessment) exhibited more pronounced impairment 
of selective attention, behavioral inhibition, working memory, and goal-directed behavior.

\section{Intelligence and Academic Achievement}

Since the dietary treatment for PKU was established, researchers have explored the quality of mental development in patients with PKU. Dobson et al. (1976) reported a discrepancy in the IQ of PKU children and their family members. Later studies proposed that intellectual function was related to dietary control, as children with good dietary control had comparable IQs to their non-affected siblings in the first years of life. While appropriate dietary control may result in normal intelligence, academic skills, specifically language and arithmetic, may be impaired (Fishler et al. 1987; Moyle et al. 2007).

Azen et al. (1996), who followed 120 children with PKU, discovered higher language scores in children that maintained better control of blood Phe concentrations than children who discontinued or liberalized the diet (Azen et al. 1996; Williams et al. 2008). Brumm et al. (2004) reported a positive correlation between years on diet and verbal fluency, expressive naming, and receptive vocabulary in 24 adults with PKU. Those with Phe over $1000 \mu \mathrm{mol} / \mathrm{L}$ at the time of testing scored significantly lower on these measures than those with Phe below $1000 \mu \mathrm{mol} / \mathrm{L}$ (Brumm et al. 2004). However, multiple studies demonstrate a reduction in language scores over time for all groups with PKU, despite the quality of treatment (Gassio et al. 2005; Moyle et al. 2007).

Deficits in perceptual and visual-spatial skills have also been recognized in individuals with PKU. Children with PKU showed lower detection of visual contrast than healthy controls after controlling for differences in IQ and visual acuity $(\mathrm{p}<0.005)$ (Diamond et al. 1996; Janzen and Nguyen 2010). Gassio et al. (2005) demonstrated a 
negative correlation between metabolic control during the first 6 years of life and visualspatial scores $(\mathrm{r}=-0.553, \mathrm{p}=0.008)$. Calculation and spelling skills are dependent upon visual-spatial recognition, visual perception, and memory; therefore, mild deficits in visual-perceptual skills may contribute to spelling and calculation difficulties common in patients with PKU (Chang et al. 2000; Antshel 2010). Chang et al. (2000) reported out of 32 early treated patients, 19.4 percent scored below average in calculation skills. Another study reported 33 percent of students with PKU had more difficulty with mathematics and spelling than their peers (Weglage et al. 1993).

Gassio et al. (2005) demonstrated that patients with PKU receiving early and continuous dietary treatment scored significantly lower in intelligence tests than their age matched controls $(\mathrm{p}<0.0001)$. While subjects were within the normal IQ range $(102 \pm$ 9), they scored an average of 10 points lower than control subjects (112 \pm 8$)$. Differences in fine motor skills, attention problems, executive functions, and school problems were statistically significant as well. There was no correlation between individuals with school problems and dietary control for the first 6 years of life. However, those with school problems had significantly higher concurrent index of dietary control (mean of median Phe levels measured at 6-month intervals) during the last 6 months when compared to the first 6 years of life. Patients exhibiting school problems also had lower intelligence scores $(98 \pm 8 ; \mathrm{p}=0.033)$ (Gassio et al. 2005).

\section{Processing Speed}

Antshel and Waisbren (2003) described processing-speed deficits in 46 children with PKU using the Wechsler Intelligence Scale for Children (WISC)-III Coding subtest. They showed reduced speed of information processing when compared to siblings. In 
addition, studies in adolescents with early-treated PKU demonstrated impaired performance on neuropsychological tests compared with those with type 1 diabetes $(\mathrm{p}<$ 0.001). However, deficits were not due to specific cognitive abilities but were attributed to slower processing speed, which was correlated with elevated blood Phe levels (Janzen and Nguyen 2010).

Moyle et al. (2007) reported that slowed information processing is the dominant feature in adults with PKU rather than impaired executive function, even for those maintaining a Phe-restricted diet. A meta-analysis including 11 studies demonstrated patients with PKU scored an average of one SD below controls on measures on processing speed (Moyle et al. 2007). Magnetic resonance imaging (MRI) studies on 15 adults with PKU found those with an abnormal scan scored significantly lower of measures of processing speed $(p=0.018$ and 0.048) (Brumm et al. 2004). When compared to a control group, early treated adults with PKU that were currently off diet had significant differences in the Processing Speed Index (PSI) and the Perceptual Organization Index (POI) of the Wechsler Adult Intelligence Scale-III (WAIS)-III. There was no significant correlation between POI and PSI and lifetime Phe levels, which supports the hypothesis that adults with PKU may have reduced processing speed regardless if they continue the Phe-restricted diet (Moyle et al. 2007).

Weglage et al. (1999) indicated that there is decreased susceptibility to the damaging effects of elevated Phe concentrations as patients with PKU become older. Twenty adolescent patients with PKU and 20 controls were administered a test measuring IQ twice at mean ages 11 and 14 years. The initial test showed a significant negative correlation between lifetime Phe levels and performance $(r=-0.33, p<0.05)$. Despite 
significantly elevated Phe concentrations during the second exam, the patient scores improved 4-6 points from the first exam (Weglage et al. 1999). Brumm et al. (2004) also reported cognitive deficits in adults were more highly correlated with treatment history rather than current Phe levels. This does not encourage the removal of dietary treatment during adolescence, but it suggests relaxation of diet may not result in progression of neuropsychological deficits.

Pietz et al. (1997) suggested that adults with PKU may have an increased prevalence of psychiatric disorders despite continuing dietary treatment. When comparing 35 adults with PKU to a control group of 181 18-year-old subjects, 25.7 percent of those with PKU exhibited psychiatric disorders compared to 16.1 percent of controls. The psychiatric symptoms included depressed mood, phobias, generalized anxiety, hypochondria worries, and anxiety at work (Pietz et al. 1997). However, a study comparing women who were late-treated or off-diet with early- and continuously-treated women demonstrated significantly higher scores on measures of social introversion and psychopathology than the early-treated group (Brumm and Grant 2010).

\section{Late-Treated PKU}

While brain damage from elevated Phe concentrations cannot be reversed, latediagnosed patients (mean age 2.44 years) may still benefit from dietary therapy (Trefz et al. 2000). Koch et al. (1999) showed that out of 28 late but well treated patients, 18 were able to live independently as adults without residential care. The initial measures of IQ $(52.7 \pm 16.1)$ in a group of 40 late-treated patients positively correlated with final measures of IQ in adulthood $(79 \pm 16.4)(\mathrm{p}<0.0001)$. The degree of brain damage may 
be reflected in the initial measures of IQ, thus gaining some predictive value for estimating the IQ in adults.

\section{Pathophysiology of Brain Dysfunction}

The influence of neurotoxic agents or metabolites on the developing brain is dependent on two factors: ability to access the nervous system and timing of exposure. The brain is less vulnerable to environmental insults if it occurs before or after development (Rice and Barone 2000). Different areas of the brain mature on distinctive timelines during pre- and postnatal periods. Numerous studies corroborate that neuronal development in humans continues from early embryogenesis throughout adolescence. In addition, remodeling and change to the nervous system continues beyond adolescence into adulthood in response to environmental and genetic stimuli (Rice and Barone 2000).

The development process of the central nervous system is comprised of a series of chronological and parallel events. Disturbance of one event may impact later development. The neurodevelopmental consequences of exposure to elevated Phe are dependent on the timing and degree of the exposure. Therefore, the age at which exposure occurs and the duration of the exposure contribute to the extent of brain dysfunction in those with PKU (Antshel and Waisbren 2003).

There are several hypotheses explaining the etiology of brain damage and impairment in intelligence and executive functioning skills in those with PKU. These include impaired myelination, white matter lesions, and dopamine depletion in the prefrontal cortex. Elevated Phe and low Tyr seen in PKU are believed to impair myelination (Dyer 2000; Gassio et al. 2005; Anderson et al. 2007). Oligodendrocytes, which are necessary for the assembly and maintenance of myelin, are sensitive to high 
Phe. The development of oligodendrocytes occurs after that of the neurons in a given structure. The progression of myelination continues through adolescence, which lengthens the period by which elevated Phe may be more detrimental (Rice and Barone 2000). If the myelination process is affected, the speed of the action potentials would be decreased, causing slowed information processing (Moyle et al. 2007).

Reiss et al. (1996) used MRI scans to describe brain maturation in 85 healthy children aged 5 to 17 years. Human brains reach adult weight by approximately 5 to 10 years of age. However, cortical grey matter and cerebral white matter volumes change throughout childhood. The amount of cortical grey matter began to decrease in participants as young as 5 years, suggesting the refinement of neuronal connections that occurs naturally in healthy children. As cortical grey matter decreases, increased myelination is thought to promote the synthesis of cerebral white matter. This expansion of white matter was found mostly in the prefrontal cortex of the brain, which is known to have substantial myelination during late childhood and early adulthood (Reiss et al. 1996).

Disturbed myelin synthesis and increased myelin turnover are proposed to be involved in the etiology of white matter lesions (Anderson et al. 2007). The majority of PKU patients, both early treated and untreated, display some degree of white matter abnormality (Anderson et al. 2007; Williams et al. 2008). Dyer (1999) suggested elevated Phe stalls myelination, resulting in severe hypomyelination if untreated. Myelination is thought to progress normally in early treated patients. Therefore, white matter abnormalities in this group are attributed to demyelination or dysmyelination of previously formed myelin (Dyer 1999; Anderson and Leuzzi 2010). 
The initial pathological change in myelin associated with elevated Phe levels involves splaying of the myelin lameliae within the sheath, increasing the water content. The structural change and increased water content produce the typical MRI scan appearance of abnormal white matter (Cleary et al. 1995). Anderson et al. found severity of white matter abnormalities to be a significant predictor of executive functioning and attention factors $(\mathrm{RC}=-0.40, \mathrm{p}=0.04)$ (Anderson et al. 2007). Feldmann et al. (2002) demonstrated those with PKU had slower responses compared with non-PKU controls, which was attributed to white matter abnormalities.

The degree of white matter abnormality detected by MRI scans was closely associated with concurrent blood Phe concentrations. These abnormalities are partially reversible with reduction of blood Phe levels. Cleary et al. (1995) showed a decrease in the white matter change in 14 out of 41 patients with PKU. The decrease in severity correlated both with the reduction in Phe between scans and the level of Phe attained, as changes were only observed in those with Phe levels less than $900 \mu \mathrm{mol} / \mathrm{L}$. The earliest MRI changes were recognized after 2 months, likely related to myelin turnover times.

Neurotransmitters also play integral roles in brain development. It has been hypothesized that certain critical periods of brain maturation require adequate exposure to neurotransmitters (Pascucci et al. 2008). Neurotransmitters function differently during development compared to adulthood. In adults, neurotransmitters mediate the transmission across synapses. While this role is the same during development, they must interact with receptors over a greater distance. Neurotransmitters are also required to form a gradient necessary for pattern formation of numerous regions of the nervous system and for differentiation of neurotransmitter systems (Rice and Barone 2000). 
Therefore, deficits in neurotransmitters during these critical periods caused by PKU may impair brain maturation resulting in cognitive delay. Elevated plasma Phe concentrations have been associated with lower levels of dopamine, norepinephrine, and serotonin (Pascucci et al. 2008).

Pascucci et al. (2008) tested this hypothesis by measuring the availability of neurotransmitters in mice with induced PKU. Healthy mice exhibited peak production of neurotransmitters during the third week of life, which coincided with the critical period for synapse formation and dendritic growth in the rodents' cortices. Mice with PKU demonstrated approximately 50 percent fewer neurotransmitters than healthy mice. The results indicate age-dependent deficits in neurotransmitters during development in the mouse model of PKU.

Dopamine depletion has been reported in early and continuously treated patients with PKU (Anderson et al. 2007). Compared to other regions of the brain, the prefrontal cortex is thought to be particularly sensitive to mild decreases in dopamine, as it has the highest proportion of cerebral dopamine turnover. Patterns of activity in the prefrontal cortex of the brain are responsible for executive function skills (Moyle et al. 2007). If this area were impaired, one would only perceive isolated events without attention to other details, which explains the potential for poor planning and organizational skills in those with PKU. Brain motor tract functions are also dependent on dopamine (Arnold et al. 2004). Gassio et al. (2005) reported a negative correlation with blood Phe levels and motor function on the day of their study $(r=-0.427, p=0.033)$, which may indicate a link between dopamine depletion and elevated Phe. 
Rice and Barone (2000) report that neurotoxic agents may cause a developmental insult that is not clinically detected until much later in life, such as exposure to methyl mercury or X-ray radiation. Developmental delays or transient delays could be masked by temporary compensation from continued growth of the nervous system. Manifestation occurs later in life when the body's compensatory ability decreases with aging and the brain undergoes loss of neurons and synaptic inputs (Rice and Barone 2000). The potential for latent neurotoxicity has not been determined for patients with PKU (Frank et al. 2007).

\section{Dietary Therapy}

In the 1950s, Horst Bickel developed the primary treatment for PKU involving a Phe-restricted diet. It dramatically changed the prognosis of PKU patients. However, the initiation of therapy must occur early in life, as dietary treatment will not reverse any neurological damage that has occurred (Burgard et al. 2009). Strict adherence to a Pherestricted diet and supplemental medical formula prevents the debilitating consequences of the disease. However, the treatment regimen is arduous, requiring regular collection of blood samples, detailed food records, frequent appointments with a metabolic team, and maintenance of a highly restrictive diet (Bilginsoy et al. 2005).

In infants, small amounts of Phe from breast milk and/or commercial infant formulas are provided along with a Phe-free medical formula to meet calorie and protein needs (Williams et al. 2008). In older children, dietary Phe intake must be calculated based on the child's plasma Phe concentration, age, growth rate, state of health, and protein and calorie requirements (Acosta and Yannicelli 2001). Tolerance to Phe is determined by gradually increasing prescribed phenylalanine and monitoring blood Phe 
concentrations (Burgard et al. 2009). Dietary Phe intake may be measured using mg Phe, food equivalents (15mg Phe each), or grams of protein ( $1 \mathrm{~g}$ of protein corresponding to approximately $50 \mathrm{mg}$ Phe). High protein foods such as eggs, meat, cheese, dried beans, legumes, and milk must be avoided. Aspartame, a common artificial sweetener, should also be avoided as Phe is cleaved from aspartic acid when metabolized (Williams et al. 2008).

Caloric intake should also be considered, as it plays a primary role in nitrogen retention. Inadequate consumption of energy results in a negative nitrogen balance even if protein intake is adequate. This is particularly concerning during illness due to loss of appetite and subsequent catabolism, which releases Phe into the bloodstream (Przyrembel and Bremer 2000). Calorie requirements are met using the prescribed protein intake, medical formula, and foods free of phenylalanine.

As children and adolescents grow, their calorie and protein needs increase. However, their prescribed Phe does not typically increase proportionally. Wendel et al. (1990) analyzed the average protein and Phe intakes needed to maintain appropriate plasma Phe in children from birth to six years of age. These children consumed an average of $2.26 \mathrm{~g}$ protein per $\mathrm{kg}$ body weight at 6 months and $1.81 \mathrm{~g} / \mathrm{kg}$ at 6 years. Mean Phe intakes declined from $34 \mathrm{mg}$ Phe/kg body weight at 6 months to $15 \mathrm{mg} / \mathrm{kg}$ at 6 years. The participants' protein intake per kg body weight decreased by approximately 20 percent whereas Phe intake dropped approximately 56 percent (Wendel et al. 1990). An individual's protein needs are met with the use of a Phe-free elemental formula in addition to natural protein. Phenylalanine-free amino acid modules typically provide 80 to 85 percent of an individual's daily protein requirements in addition to 
necessary macro- and micronutrients. However, the optimal dosage has yet to be determined (MacDonald et al. 2006). It has been hypothesized that a higher amount of protein substitute ( $2 \mathrm{~g} / \mathrm{kg} /$ day) may lead to increased protein retention and compensate for the potential for poor utilization of free amino acids. Free amino acids are absorbed and oxidized faster than natural protein; therefore medical formula should be divided into three doses per day to enhance utilization of amino acids (MacDonald et al. 2006; Olsson et al. 2007). MacDonald et al. (2006) showed improved Phe control for those taking 2 $\mathrm{g} / \mathrm{kg} /$ day of protein substitute compared to those taking $1.2 \mathrm{~g} / \mathrm{kg} /$ day. However, these results conflict with previous research.

A new alternative to free amino acid modules is glycomacropetide (GMP), which is the first intact source of low-phenylalanine protein (van Calcar et al. 2009). GMP is a 64-amino acid glycophosphopeptide found in whey protein during cheese making. It is produced when kappa-casein is metabolized into para-casein, which remains in the curd and GMP in the whey. While pure GMP is free of phenylalanine, the Phe content of the commercial form of GMP is 2.5 to $5.0 \mathrm{mg}$ Phe per gram of protein (Ney et al. 2009). GMP contains 2 to 3 fold greater amounts of the large neutral amino acids (LNAA) isoleucine and threonine compared to other protein sources.

GMP foods may be designed to constitute one half of the required protein from Phe-free medical formulas for those of school age or older (Ney et al. 2009). The results of blind taste tests demonstrated a preference for GMP products over various amino acid supplements in those with PKU (van Calcar et al. 2009). Potential benefits of GMP include increased protein retention and improved use of amino acids for protein synthesis by delaying the absorption of amino acids. 
While a Phe-restricted diet with amino acid supplementation is indicated for those with PKU, it does present potential risks. Patients with PKU undergoing dietary therapy have an abnormal fatty acid profile and low levels of cholesterol and trace elements such as iron, zinc, and retinol (Przyrembel and Bremer 2000; Williams et al. 2008). Patients with PKU exclude the majority of animal products, which supply exogenous cholesterol, fatty acids, and micronutrients (Przyrembel and Bremer 2000). However, it is unclear whether these disturbances are due to inadequate intake or disordered biosynthesis of these nutrients (Williams et al. 2008).

Research has established that maintenance of plasma Phe through a Phe-restricted diet improves cognitive outcomes. There is also worldwide consensus that dietary treatment should be initiated in infants with plasma Phe above $10 \mathrm{mg} / \mathrm{dL}$. However, clinicians in different countries and treatment centers within the US do not agree on the optimal treatment range during different periods of life (Waisbren et al. 2007).

The United Kingdom (UK) advises infants and young children with PKU to keep Phe levels between 120 to $360 \mu \mathrm{mol} / \mathrm{L}$, with liberalization of plasma Phe control after childhood. The German Working Group for Metabolic Diseases' policy includes maintenance of Phe levels between 42 to $240 \mu \mathrm{mol} / \mathrm{L}$ in those less than 10 years of age, 42 to $900 \mu \mathrm{mol} / \mathrm{L}$ between 10 and 15 years, and 42 to $120 \mu \mathrm{mol} / \mathrm{L}$ in those over 15 years. The majority of US clinics use a treatment range of 120 to $360 \mu \mathrm{mol} / \mathrm{L}$ for those age 12 years and younger and 120 to $600 \mu \mathrm{mol} / \mathrm{L}$ for older patients (Waisbren et al. 2007).

Guidelines released by the Medical Research Council Working Party on PKU and by a National Institutes of Health Consensus Panel stated that lifelong dietary treatment is required for optimal outcomes in PKU (Wappner et al. 1999; NIH 2000). Increased 
cognitive and emotional dysfunction, behavior disorders, and neurological complications have been identified in patients with PKU who discontinue dietary therapy (Gassio et al. 2005). In addition, patients who continue a Phe-restricted diet throughout life report lower rates of asthma, mental disorders, hyperactivity and hypoactivity than those discontinuing dietary treatment (Waisbren et al. 2007).

While clinicians support the slogan "Diet for Life," it does not come without challenges, such as obtaining social support, adhering to the prescribed diet, and the risk of developing nutrient imbalances (Williams et al. 2008). Patient compliance to dietary recommendations tends to decrease after early childhood (Weglage et al. 1992). Wendel et al. (1990) reported a steady decrease in frequency of blood Phe level monitoring after 6 months of age. In addition to reduced blood Phe monitoring, there is a continual increase in Phe concentrations as patients age. An observational study of Phe levels in 330 patients under 20 years of age reported 30 percent of blood Phe concentrations above the recommended maximum value in children less than 4 years of age (Walter et al. 2002). This number increased to 80 percent of levels in adolescents between 15 and 19 years. The mean of median Phe levels for the participants less than 15 years gradually increased with age but remained within the recommended concentrations. However, those aged 15 to 19 years had a mean median Phe above the treatment range.

\section{Sapropterin Therapy}

An alternative to using a Phe-restricted diet as the sole therapy for PKU is the use of sapropterin dihydrochloride, the pharmacological equivalent of $\mathrm{BH}_{4}$. A randomized, double-blind, placebo-controlled clinical trial on the efficacy of sapropterin dihydrochloride treatment demonstrated decreased blood Phe concentrations in patients 
with PKU (Trefz et al. 2009). Only a portion (approximately 50 percent in mild PKU and $<10$ percent in classic PKU) of patients responded to the treatment, as some lack adequate amounts of residual enzyme activity required for this therapy to be effective (Blau et al. 2009). In order to be determined responsive to sapropterin therapy, blood Phe must decrease at least 30 percent from baseline levels. Treatment with this medication often allows patients to increase their intake of natural protein sources, which could improve nutritional balance. Sapropterin has been shown to be safe in patients 4 years and older at doses up to $20 \mathrm{mg} / \mathrm{kg} /$ day (Trefz et al. 2009).

\section{Enzyme Replacement Therapy}

Those patients that do not respond to $\mathrm{BH}_{4}$ therapy may benefit from enzyme replacement therapy, which is not dependent on residual PAH activity. A therapy under investigation involves the substitution of $\mathrm{PAH}$ with pegylated phenylalanine ammonia-lyase (PEG-PAL) (enzyme substitution therapy), which has shown some benefit in mouse models. Biomarin Pharmaceutical Inc. is currently facilitating clinical trials using PEG-PAL to treat patients with PKU who are unresponsive to BH4 therapy (Williams et al. 2008).

\section{Treatment with Large Neutral Amino Acids}

Large neutral amino acids (LNAAs) (phenylalanine, tyrosine, tryptophan, threonine, isoleucine, leucine, valine, methionine, arginine, lysine, and histidine) share the same cationic transporter protein to cross the blood brain barrier (Matalon et al. 2007; Schindeler et al. 2007). These amino acids compete for access to the same transporter protein and are driven by a concentration gradient. It is postulated that supplementation with large doses of LNAAs with the exception of phenylalanine would reduce the entry 
of phenylalanine into the brain (Matalon et al. 2007). Schindeler et al. (2007)

demonstrated a modest decrease in plasma Phe in patients with PKU not taking medical formula but no effect in those taking medical formula. This suggests LNAA therapy may be most beneficial for those unable to comply with dietary restrictions.

\section{CONCLUSION}

While early treatment with a Phe-restricted diet prevents the most profound consequences of PKU, it may not avert mild deficits in executive and intellectual functioning. These impairments impact attention span, processing speed, visual-spatial abilities, and language (Janzen and Nguyen 2010). Patients with PKU may exhibit symptoms similar to ADHD, work less efficiently, have difficulty understanding charts and diagrams, and have problems with articulation or comprehension of oral and written materials. In addition, impaired executive abilities may inhibit use of executive strategies to enhance learning and memory (Janzen and Nguyen 2010). The precise pathophysiology of deficits in PKU has not been determined, but there are several theories including impaired myelination, white matter abnormalities, and dopamine depletion. White matter abnormalities in patients with PKU detected through MRI scans are partially reversible by decreasing blood Phe to an acceptable range (Cleary et al. 1995).

It has been established that optimal metabolic control during the neonatal period and early childhood is positively associated with intelligence (Brumm and Grant 2010). Patient adherence to diet recommendations decreases after this period (Weglage et al. 1992). This is concerning, as brain development continues from early embryogenesis throughout adolescence. Elevated Phe may be detrimental even in adulthood, which 
explains clinical recommendations for lifelong dietary therapy (Wappner et al 1999; NIH 2000).

\section{REFERENCES}

Acosta PB, Yannicelli S (2001) Nutrition Support Protocols, $4^{\text {th }}$ ed. Columbus, Ohio: Ross Products Division, Abbott Laboratories.

Anderson PJ, Leuzzi V (2010) White matter pathology in phenylketonuria. Mol Genet Metab 99: S3-S9.

Anderson PJ, Wood SJ, Francis DE, Coleman L, Anderson V, Boneh A (2007) Are neuropsychological impairments in children with early-treated phenylketonuria related to white matter abnormalities or elevated phenylalanine levels? Developmental Neuropsychology 32: 645-668.

Antshel KM (2010) ADHD, learning, and academic performance in phenylketonuria. Mol Genet Metab 99: S52-S58.

Antshel KM, Waisbren SE (2003) Timing is everything: executive functions in children exposed to elevated levels of phenylalanine. Neuropsychology 17: 458-468.

Arnold GL, Vladutiu CJ, Orlowski CC, BlakelyM, DeLuca J (2004) Prevalence of stimulant use for attentional dysfunction in children with phenylketonuria. J Inderit Metab Dis 27: 137-143.

Azen C, Koch R, Friedman E, Wenz E, Fishler K (1996) Summary of findings from the United States Collaborative Study of children treated for phenylketonuria. Eur J Pediatr 155: S29-S32.

Bilginsoy C, Waitzman N, Leonard CO, Ernst SL (2005) Living with Phenylketonuria: perspectives of patients and their families. J Inderit Metab Dis 28: 639-649.

Blau N, Belanger-Quintana A, Demirkol M, Feillet F, Giovannini M, MacDonald A, Trefz FK, van Spronsen FJ (2009) Optimizing the use of sapropterin (BH4) in the management of phenylketonuria. Mol Genet Metab 96: 158-163.

Brumm VL, Azen C, Moats RA, Stern AM, Broomand C, Nelson MD, Koch R (2004) Neuropsychological outcome of subjects participating in the PKU Adult Collaborative Study: a preliminary review. J Inherit Metab Dis 27: 549-566.

Brumm VL, Grant ML (2010) The role of phenylketonuria: a review of research and management. Mol Genet Metab 99: S18-S21. 
Burgard P, Luo Xiaoping, Hoffmann GF (2009) Phenylketonuria. In: Sarafoglou K, Hoffman GF, Roth KS, eds. Pediatric Endocrinology and Inborn Errors of Metabolism. New York: McGraw Hill Companies, pp 163-168.

Chang P, Gray RM, O’Brien LL (2000) Patterns of academic achievement among patients treated early with phenylketonuria. Eur J Pediatr 159: S96-S99.

Cleary MA, Walter JH, Wrath JE, Jenkins JPR (1995) Magnetic resonance imaging in phenylketonuria: reversal of cerebral white matter change. J Pediatr 127: 251-255.

Diamond A, Herzberg C (1996) Impaired sensitivity to visual contrast in children treated early and continuously for phenylketonuria. Brain 119: 523-538.

Dobson JC, Kushida E, Williamson M, Friedman EG (1976) Intellectual performance of 36 phenylketonuria patients and their nonaffected siblings. Pediatrics 58: 53-58.

Dyer CA (1999) Pathophysiology of phenylketonuria. Ment Retard Dev Disabil Res Rev 5: 104-112.

Dyer CA (2000) Comments on the neuropathology of phenylketonuria. Eur J Pediatr 159 (Suppl 2): S107-S108.

Feillet F, MacDonald A, Hartung D, Burton B (2010) Outcomes beyond phenylalanine: an international perspective. Mol Genet Metab 99: S79-S85.

Feldmann R, Denecke J, Pietsch M, Grenzebach M, Weglage J (2002) Phenylketonuria: no specific frontal lobe-dependent neuropsychological deficits in early-treated patients in comparison with diabetics. Pediatr Res 51: 761-765.

Fishler K, Azen C, Henderson R, Friedman EG, Koch R (1987) Psychoeducational findings among children treated for phenylketonuria. Am J Ment Defic 92: 65-73.

Frank N, Fitzgerald R, Legge M (2007) Phenylketonuria - the lived experience. NZMJ 120: 2728.

Gassio R, Artuch R, Vilaseca MA, Fuste E, Boix C, Sans A, Campistol J (2005) Cognitive functions in classic phenylketonuria and mild hyperphenylalaninaemia: experience in a pediatric population. Developmental Medicine and Child Neurol 47: 443448.

Gassio R, Fuste E, Lopez-Sala A, Artuch R, Vilaseca MA, Campistol J (2005) School performance in early and continuously treated phenylketonuria. Pediatr Neurol 33: 267271.

Janzen D, Nguyen M (2010) Beyond executive function: non-executive cognitive abilities in individuals with PKU. Mol Genet Metab 99: S47-S51. 
Koch R, Moseley K, Ning J, Romstad A, Guldberg P, Guttler F (1999) Long-term beneficial effects of the phenylalanine-restricted diet in late-diagnosed individuals with phenylketonuria. Mol Genet Metab 67: 148-155.

Leuzzi V, Pansini M, Sechi E (2004) Executive impairment in early-treated PKU subjects with normal mental development. J Inherit Metab Dis 27: 115-125.

MacDonald A, Chakrapani A, Hendriksz C, Daly A, Davies P, Asplin D, Hall K, Booth IW (2006) Protein substitute dosage in PKU: how much do young patients need? Arch Dis Child 91: 588-593.

Matalon R, Michals-Matalon K, Bhatia G, Burlina AB, Burlina AP, Braga C, Flori L, Glovannini M, Grechanina E, Novikov P, Grady J, Tyring SK, Guttler F (2007) Double blind placebo control trial of large neutral amino acids in treatment of PKU: effect on blood phenylalanine. J Inherit Metab Dis 30: 153-158.

Moyle JJ, Fox AM, Arthur M, Byneveldt M, Burnett JR (2007) Meta-analysis of neuropsychological symptoms of adolescents and adults with PKU. Neuropsychol Rev 17: 91-101.

Moyle JJ, Fox AM, Bynevelt M, Arthur M, Burnett JR (2007) A neuropsychological profile of off-diet adults with phenylketonuria. J Clinical and Experimental Neuropsychology 29: 436-441.

Ney DM, Gleason ST, van Calcar SC, MacLeod EL, Nelson KL, Etzel MR, Rice GM, Wolff JA (2009) Nutritional management of PKU with glycomacropeptide from cheese whey. J Inherit Metab Dis 32: 32-39.

NIH (2000) Phenylketonuria (PKU): screening and management. NIH Consensus Statement 17: 1-33.

Olsson GM, Montgomery SM, Alm J (2007) Family conditions and dietary control in phenylketonuria. J Inherit Metab Dis 30: 708-715.

Pascucci T, Andolina D, Ventura V, Puglisi-Allegra S, Cabib S (2008) Reduced availability of brain amines during critical phases of postnatal development in a genetic mouse model of cognitive delay. Brain Res 1217: 232-238.

Pietz J, Fatkenheuer B, Burgard P, Armbruster M, Esser G, Schmidt H (1997) Psychiatric disorders in adult patients with early-treated phenylketonuria. Pediatrics 99: 345-350.

Przyrembel H, Bremer HJ (2000) Nutrition, physical growth, and bone density in treated phenylketonuria. Eur J Pediatr 159: S129-S135. 
Reiss AL, Abrams MT, Singer HS, Ross JL, Denckla MB (1996) Brain Development, Gender, and IQ in Children. Brain 119: 1763-1774.

Rice D, Barone S (2000) Critical Periods of Vulnerability for the Developing Nervous System: Evidence from Humans and Animal Models. Environ Health Perspect 108: S511-S533.

Schindeler S, Ghosh-Jerath S, Thompson S, Rocca A, Joy P, Kemp A, Rae C, Green K, Wilcken B, Christodoulou J (2007) The effects of large neutral amino acid supplements in PKU: an MRS and neuropsychological study. Mol Genet Metab 91: 48-54.

Sharman R, Sullivan K, Young R, McGill J (2009) Biochemical markers associated with executive function in adolescents with early and continuously treated phenylketonuria. Clin Genet 75: 169-174.

Trefs FK, Burton BK, Longo N, Casanova MM, Gruskin DJ, Dorenbaum A, Kakkis ED, Crombez EA, Grange DK, Harmatz P, Lipson MH, Milanowski A, Randolph LM, Vockley J, Whitley CB, Wolff JA, Bebchuk J, Christ-Schmidt H, Hennermann JB (2009) Efficacy of sapropterin dihydrochloride in increasing phenylalanine tolerance in children with phenylketonuria: a Phase III, randomized, double-blind, placebo-controlled study. J Pediatr 154: 700-707.

Trefz FK, Cipcic-Schmidt S, Koch R (2000) Final intelligence in late treated patients with phenylketonuria. Eur J Pediatr 159: S145-S148.

van Calcar SC, MacLeod EL, Gleason ST, Etzel MR, Clayton MK, Wolff JA, M Ney D (2009) Improved nutritional management of phenylketonuria by using a diet containing glycomacropeptide compared with amino acids. Am J Clin Nutr 89: 1068-77.

van Spronsen FJ, Enns GM (2010) Future treatment strategies in phenylketonuria. Mol Genet Metab 99: S90-S95.

Waisbren S, Noel K, Fahrbach K, Cella C, Frame D, Dorenbaum A, Levy H (2007) Phenylalanine blood levels and clinical outcomes in phenylketonuria: a systematic literature review and meta-analysis. Mol Genet Metab 92: 63-70.

Walter JH, White FJ, MacDonald A, Rylance G, Boneh A, Francis DE, Shortland GJ, Schmidt M, Vail A (2002) How practical are recommendations for dietary control in phenylketonuria? Lancet 360: 55-57.

Wappner R, Cho S, Kronmal RA, Schuett V, Seashore MR (1999) Management of phenylketonuria for optimal outcome: a review of guidelines for phenylketonuria management and a report of surveys of parents, patients, and clinic directors. Pediatrics 104:e68. 
Weglage J, Funders B, Wilken B, Schubert D, Schmidt E, Burgard P, Ullrich K (1992) Psychological and social findings in adolescents with phenylketonuria. Eur J Pediatr 151: 522-525.

Weglage J, Funders B, Wilken B, Schubert D, Ullrich K (1993) School performance and intellectual outcome in adolescents with phenylketonuria. Acta Paediatr 82: 582-586.

Weglage J, Pietsch M, Sprinz A, Feldmann R, Grenzebach M, Ullrich K (1999) Regression of neuropsychological deficits in early-treated phenylketonurics during adolescence. J Inher Metab Dis 22: 693-705.

Wendel U, Ullrich K, Schimdt H, Batzler U (1990) Six-year follow up of phenylalanine intakes and plasma phenylalanine concentrations. Eur J Pediatr 149 (Suppl 1): S13-S16.

Williams RA, Mamotte CD, Burnett JR (2008) Phenylketonuria: an inborn error of metabolism. Clin Biochem Rev 29: 31-40. with permission of the Australian Association of Clinical Biochemists. 
CHAPTER 3

\author{
CORRELATION OF AGE-SPECIFIC PHENYLALANINE LEVELS ON \\ INTELLECTUAL OUTCOME IN PATIENTS WITH PHENYLKETONURIA
}

\begin{abstract}
\end{abstract}
It is widely appreciated by the medical community that subtle deficits in intellect, academic skills and executive functioning exist in early treated phenylketonuria (PKU). In this study, we described the relationship between intellectual outcome and concentration/variation in blood phenylalanine (Phe) during specific developmental periods ( $0-5$ years, 6-10 years, $>10$ years). We also examined the association between mean number of blood Phe samples and maintenance of Phe within treatment range (120$360 \mu \mathrm{mol} / \mathrm{L}$ ) and within one standard deviation (SD) of index of dietary control, defined as the mean of 12-month median Phe. Retrospective data was collected from 55 patients receiving treatment at the University of Utah Metabolic Clinic. Index of dietary control (IDC) and SD blood Phe steadily increased and mean number of samples decreased during each developmental period. The correlation between IDC during 6-10 years of life and perceptual reasoning was $-.370(\mathrm{p}=0.006)$. Using multivariate linear regression, IDC during 0-5 years and 6-10 years were associated with a 0.5-point decrease and 0.3point decrease in perceptual reasoning scores for every $100 \mu \mathrm{mol} / \mathrm{L}$ increase in blood Phe, though associations were nonsignificant $(\mathrm{p}=0.067 ; 0.082)$. SD of Phe was not associated with any measure of intelligence. The likelihood of IDC $>360 \mu \mathrm{mol} / \mathrm{L}$ in those 6-10 years was $32.3 \%$ lower for each additional blood Phe sample per year $(\mathrm{p}=$ 0.001). The present study suggests frequent blood Phe monitoring during ages 6-10 years may reduce blood Phe and prevent deficits in perceptual reasoning later in life. 
INTRODUCTION

Phenylketonuria (PKU; OMIM 262600) is an autosomal recessive disorder characterized by impaired phenylalanine (Phe) metabolism due to a deficiency of phenylalanine hydroxylase (PAH; EC 1.14.16.1) or defective synthesis/recycling of its cofactor tetrahydrobiopterin. PKU impairs the conversion of Phe to tyrosine (Tyr), resulting in a neurotoxic accumulation of Phe and a deficiency of Tyr (Waisbren et al. 2007; Burgard et al. 2009). Consequently, profound mental retardation ensues if untreated. Treatment is initiated in the newborn period, which consists of a protein- or Phe-restricted diet supplemented with Phe-free amino acid modules and frequent monitoring of blood Phe levels (Waisbren et al. 2007). Recommended treatment range for blood Phe is between 120 and $360 \mu \mathrm{mol} / \mathrm{L}$. Lifelong continuation of dietary therapy is recommended for optimal outcomes (Wappner et al. 1999; NIH 2000).

The neurodevelopmental consequences of elevated Phe are dependent on the timing and degree of the exposure. Therefore, the age of occurrence and the duration of the exposure contribute to the extent of brain dysfunction in those with PKU (Antshel and Waisbren 2003). Different areas of the brain mature on distinctive timelines during preand postnatal periods. Numerous studies confirm that neuronal development in humans continues from early embryogenesis throughout adolescence (Rice and Barone 2000). The precise pathophysiology of PKU remains under investigation, but hypotheses include impaired myelination, white matter lesions, and dopamine depletion in the prefrontal cortex (Dyer 2000; Feldmann et al. 2002; Gassio et al. 2005; Anderson et al. 2007; Anderson and Leuzzi 2010; White et al. 2010). 
While the most deleterious effects of PKU can be prevented with early and continuous treatment, multiple studies corroborate the presence of subtle deficits in intelligence, academic achievement, and executive functioning in early treated patients (Stemerdink et al. 2000). These patients typically achieve average intelligence, but score lower than the general population (Fishler et al. 1987; Gassio et al. 2005; Moyle et al. 2007; Gentile et al. 2010; White et al. 2010). Deficits specifically affect language skills, visual-spatial abilities, and processing speed, which may present with difficulties in reading, mathematics, spelling and slowed auditory comprehension (Chang et al. 2000; Brumm et al. 2004; Gassio et al. 2005; Feillet et al. 2010; Janzen and Nguyen 2010). A meta-analysis (Waisbren et al. 2007) documented a proportional correlation between blood Phe during ages 0 to 12 years and 0 to 18 years with intelligence quotient (IQ). Early treated patients with PKU were predicted to have a 1.3 to 3.9 point decrease in IQ for every $100 \mu \mathrm{mol} / \mathrm{L}$ increase in blood Phe (calculated as mean Phe through both 12 and 18 years). In addition, each $100 \mu \mathrm{mol} / \mathrm{L}$ increase in concurrent Phe was predictive of a 0.5 to 1.4 point decrease in IQ. A review of other longitudinal studies reported an approximate 7-point decrease in IQ for each $300 \mu \mathrm{mol} / \mathrm{L}$ increase in blood Phe for those less than 10 years of age (Burgard 2000). Studies by Anastasoaie et al. (2008) and Vilaseca et al. (2010) also suggest variability of blood Phe as a useful predictor of intelligence in PKU.

Patient compliance to dietary therapy tends to decrease after early childhood (Weglage et al. 1992; Channon et al. 2005). Several collaborative PKU studies demonstrated a continual increase in mean Phe levels in those older than 4 years of age in relation to liberalization of diet restrictions and decreased frequency of blood Phe 
monitoring (Smith and Beasley 1989; Wendel et al. 1990; Azen et al. 1996; Burgard et al. 1997). Among an observational study of 330 patients under 20 years of age, $30 \%$ of blood Phe levels were above the maximum recommended value in those less than 4 years, $50 \%$ in those 5 to 10 years, and $80 \%$ in those 15 to 19 years of age (Walter et al. 2002). This study also reported $80 \%$ of those from $0-4$ years and 5-9 years adhered to the recommended frequency of blood Phe testing compared to $<75 \%$ of those aged $10-14$ years and $<50 \%$ in those $15-19$ years.

The aim of the present study was to examine the relationship between index of dietary control (mean of 12-month median Phe) and mean standard deviation (SD) of blood Phe levels during specific developmental periods (0-5 years, 6-10 years, $>10$ years) and most recent measures of intelligence in patients with PKU. Frequency of blood Phe monitoring during each developmental period was also assessed to determine the likelihood of achieving index of dietary control (IDC) within treatment range and mean SD of blood Phe within one SD of IDC.

\section{METHODS}

\section{Subjects}

The University of Utah Metabolic Clinic, Salt Lake City, UT, treats approximately 175 patients with PKU that reside in Utah, Idaho, and Wyoming. Retrospective data was collected from 55 patients that met the following inclusion criteria: (1) dietary treatment initiated within the first 2 months of life, (2) continuous treatment, (3) age above 5 years, (4) at least one neuropsychological evaluation, (5) no maternal PKU (brain damage in utero caused by elevated maternal plasma Phe) or 
cognitive dysfunction from unrelated causes. This study was reviewed and approved by the Institutional Review Board at the University of Utah.

\section{Biochemical Methods}

Routine measurements of blood Phe concentrations were collected using the Guthrie technique and fluorometric Phe measurement until the year 2006, after which they have been analyzed by tandem mass spectrometry. Quantitative plasma amino acids were collected during appointments at the University of Utah Metabolic Clinic and were analyzed by ion-exchange chromatography. The two different methods used to analyze Phe concentrations were comparable according to a study by Gregory et al. (2007) and also by an internal study performed at Associated Regional and University Pathologists (ARUP) laboratories that conduct newborn screening and plasma amino acid analysis for the state of Utah.

Quality of metabolic control each developmental period was calculated as the mean of median blood Phe levels in 12-month intervals, referred to as the index of dietary control. Mean SD blood Phe levels were also computed in 12-month intervals. The median blood Phe was chosen over the mean blood Phe, as the median corrects for fluctuations in blood Phe due to illness (Vilaseca et al. 2010). Lifetime data consisted of the mean of all median and SD Phe levels throughout the patients' life. Only Phe levels acquired prior to the most recent measure of IQ were included in statistical analyses. Due to the known effect of concurrent Phe concentration on cognitive testing performance, Phe concentrations within 10 days of cognitive testing were assessed (de Sonneville et al. 2010). Diagnostic Phe, defined as highest pretreatment blood Phe concentration, was 
used to classify severity of PKU phenotype with levels $>1200 \mu \mathrm{mol} / \mathrm{L}$ as classic, 600 $1200 \mu \mathrm{mol} / \mathrm{L}$ as moderate, and $120-600 \mu \mathrm{mol} / \mathrm{L}$ as mild PKU (Waisbren et al. 2007).

Frequency of blood Phe monitoring was examined for each developmental period by taking the mean of the total number of samples in 12-month intervals for each developmental period and lifetime. The University of Utah Metabolic Clinic has no specific protocols regarding recommended frequency of Phe levels, though patients are typically advised to take more frequent levels during infancy and early childhood. Monthly levels are the minimum interval recommended for all patients. The advised therapeutic range is between 120 and $360 \mu \mathrm{mol} / \mathrm{L}$.

\section{Neuropsychological Assessment}

Measures of IQ, including verbal comprehension, perceptual reasoning, and processing speed, were measured using the third and fourth editions of the Wechsler Intelligence Scale for Children (WISC-III and WISC-IV) and the Wechsler Adult Intelligence Scale (WAIS-III). The standard at the University of Utah Metabolic Clinic is to complete cognitive testing on patients with PKU at ages 6,12 , and 18 years.

Due to structural differences in the WISC-IV compared to the WISC-III and the WAIS-III, certain indexes/subtests were excluded from analysis, including Full Scale IQ (Williams et al. 2003; Flanagan and Kaufman 2009). Subtests used for statistical analysis included Block Design, Symbol Search, and Verbal IQ (VIQ) or Verbal Comprehension Index (VCI). The normative sample range of the Block Design and Symbol Search subtests are a mean of 10 with a SD of 3 . The VCI mean standard score is 100 with an SD of 15. 
The Block Design subtest was used to determine perceptual reasoning abilities. It measures visual spatial reasoning and visual-constructional ability by requiring the examinee to replicate a set of printed two-dimensional geometric patterns using blocks within a specified time period (Wechsler 2003). The Symbol Search subtest involves an individual scanning a group to determine if the target symbol is present, which specifically examines mental processing speed and accuracy (Wechsler 2003; Flanagan and Kaufman 2009).

Subtests measuring perceptual reasoning and processing speed are consistent across the three tests; however, the composition of Verbal Comprehension Indexes vary. The WISC-III contains Information, Similarities, Vocabulary, and Comprehension subtests. The WISC-IV contains all but the Information subtest, whereas the WAIS-III contains all but the Comprehension subtest. The Comprehension Subtest measures social knowledge and awareness; therefore, it quantifies understanding of cause and effect, knowledge of conventional standards of behavior, common sense, acquired knowledge, verbal comprehension, and social judgment. The Information Subtest measures general knowledge, including verbal comprehension and expression, acquired knowledge, longterm memory, US cultural knowledge, academic abilities, and auditory perception of complex verbal information (Kaufman and Lichtenberger 1999; Wechsler 2003). Despite the differences in VCI subtests between the third and fourth editions of the WISC, they are highly correlated $(\mathrm{r}=0.87)$ (Flanagan and Kaufman 2009). 
Statistical Analysis

Neuropsychological scores from the WISC-III, WISC-IV and the WAIS-III were compiled for statistical analysis. Descriptive statistics were obtained for sample characteristics and data related to blood Phe and cognitive testing. Pearson product moment correlations were computed to assess the degree of association between most recent measures of intelligence and treatment variables, which included diagnostic Phe level, days of life at which dietary therapy was initiated, concurrent Phe within 10 days of testing, IDC and mean SD Phe levels during each developmental period (0-5 years, 6-10 years, $>10$ years, and lifetime).

Treatment variables in the selected developmental periods were compared using paired t-tests. The age of participants included in the sample varied from 6 to 33 years of age, with approximately $34 \%$ of participants less than 10 years of age. If the $>10$ year age group was further stratified, the number of samples in older age groups would not be sufficient for statistical analysis. In addition, Vilaseca et al. (2010) reported no significant difference in mean and SD blood Phe between 12-18 years and $>18$ years. The specified age groups were also comparable to a similar study by Anastasoaie et al. (2008).

Multivariable linear regression analysis was used to investigate a possible association between measures of intelligence and IDC and mean SD Phe levels during each developmental period. Covariates were added to the regression model stepwise to determine which combination of independent variables created the best predictive model. Parameters that were significantly related to cognitive outcomes in a bivariate regression analysis were included in the multivariate regression model. 
Multivariable logistic regression analysis was used to examine the association between mean number of Phe samples during each developmental period and IDC and mean SD Phe for each age group. Age was included as a covariate in the analysis. All statistical analyses were performed using SPSS version 18 for Windows software. A two-sided P-value of $<0.05$ was considered significant.

\section{RESULTS}

Descriptive statistics obtained for demographic data and treatment variables of the sample are shown in Tables 3-1 and 3-2. Based on the diagnostic Phe level, 66.7\% of participants were classified as having classic PKU, 18.5\% with moderate PKU, and 14.8\% with mild PKU. The mean age at most recent measure of IQ was 11.04 years. Average test scores were well within the normative sample range, which is consistent with previous research (Leuzzi et al. 2004; Gassio et al. 2005; VanZutphen et al. 2007; Gentile et al. 2010). In the current sample, $21.8 \%$ of participants scored below average on the VCI, $14.5 \%$ on the Block Design subtest, and 23.5\% on the Symbol Search subtest. Analyses included a total of 7484 blood Phe samples from all participants.

Paired t-tests were used to compare the IDC and mean SD between developmental groups. The IDC and mean SD Phe between all developmental groups were different from each other ( $p<0.05$ for all). Differences between developmental groups 0-5 and 610 or $>10$ years were most significant $(\mathrm{p}=<0.001)$. There was no difference in the SD blood Phe between $0-5$ years and $>10$ years $(p=0.932)$. Mean number of blood Phe samples between age groups 0-5 years and 6-10 years were significantly different $(\mathrm{p}=$ 0.000 ), but the number of samples between those $6-10$ years and $>10$ years were relatively stable $(\mathrm{p}=0.997)$. As noted in Table 3-1, IDC and mean SD blood Phe levels 
steadily increased while mean number of Phe samples decreased during each age group.

Change in Phe levels from birth to 19 years is shown in Figure 3-1.

Table 3-1 Description of sample demographic and treatment variables

\begin{tabular}{|c|c|c|c|c|c|}
\hline Variables & $\mathrm{N}$ & Mean & SD & Min & Max \\
\hline Age at most recent measure of intelligence (years) & 55 & 11.04 & 4.59 & 6 & 22 \\
\hline Diagnostic Phe $(\mu \mathrm{mol} / \mathrm{L})$ & 54 & 1698 & 829 & 361 & 3789 \\
\hline Initiation of diet therapy (days of life) & 51 & 14.27 & 6.74 & 5 & 30 \\
\hline \multicolumn{6}{|l|}{ Index of Dietary Control $(\mu \mathrm{mol} / \mathrm{L})^{\mathrm{a}}$} \\
\hline Lifetime & 55 & 417 & 165 & 167 & 907 \\
\hline Age $0-5$ years & 55 & 361 & 127 & 155 & 817 \\
\hline Age $6-10$ years & 54 & 442 & 196 & 100 & 982 \\
\hline Age $>10$ years & 31 & 595 & 258 & 165 & 1174 \\
\hline Concurrent Phe (within 10 days of cognitive testing) & 37 & 631 & 374 & 42 & 1774 \\
\hline \multicolumn{6}{|l|}{ Mean number of blood Phe samples ${ }^{b}$} \\
\hline Lifetime & 55 & 10.9 & 4.1 & 3.95 & 23.7 \\
\hline Age $0-5$ years & 55 & 16.5 & 8.3 & 5.75 & 62 \\
\hline Age $6-10$ years & 54 & 7.4 & 3.6 & 1.8 & 16 \\
\hline Age $>10$ years & 31 & 6.9 & 3.9 & 2 & 21 \\
\hline \multicolumn{6}{|l|}{ Most recent measure of intelligence (WISC/WAIS) ${ }^{\mathrm{c}}$} \\
\hline Verbal Comprehension Index & 55 & 99.2 & 13.6 & 69 & 132 \\
\hline Block Design Subtest & 55 & 9.3 & 2.6 & 4 & 16 \\
\hline Symbol Search Subtest & 51 & 9.3 & 2.9 & 1 & 14 \\
\hline
\end{tabular}

Phe, phenylalanine; SD, standard deviation; WISC, Wechsler Intelligence Scale for Children; WAIS, Wechsler Adult Intelligence Scale

${ }^{a}$ Index of Dietary Control defined as mean 12-month median for each patient during the specified time frame

${ }^{\mathrm{b}}$ Mean number of Phe samples defined as mean of total Phe samples in 12-month intervals during specified ages

${ }^{c}$ Most recent measures intelligence defined as the mean compiled scores of one of three cognitive tests for each patient: WISC-III, WISC-IV, or WAIS-III 
Table 3-2 Distribution of demographic and treatment variables

\begin{tabular}{|c|c|c|}
\hline Variables & $\mathrm{N}$ & $\%$ \\
\hline \multicolumn{3}{|l|}{ Sex } \\
\hline Male & 27 & 49 \\
\hline Female & 28 & 51 \\
\hline \multicolumn{3}{|l|}{ Classification of PKU severity based on diagnostic level ${ }^{\text {a }}$} \\
\hline Classic $(>1200 \mu \mathrm{mol} / \mathrm{L})$ & 36 & 66.7 \\
\hline Moderate $(600-1200 \mu \mathrm{mol} / \mathrm{L})$ & 10 & 18.5 \\
\hline Mild (120-600 $\mu \mathrm{mol} / \mathrm{L})$ & 8 & 14.8 \\
\hline \multicolumn{3}{|c|}{ Index of Dietary Control within treatment range $(120-360 \mu \mathrm{mol} / \mathrm{L})^{\mathrm{b}}$} \\
\hline Age $0-5$ years & 34 & 61.8 \\
\hline Age 6-10 years & 22 & 40.7 \\
\hline Age $>10$ years & 6 & 19.4 \\
\hline \multicolumn{3}{|l|}{ Most recent measure of intelligence (WISC/WAIS) } \\
\hline Verbal Comprehension Index - below average scores ${ }^{c}$ & 12 & 21.8 \\
\hline Block Design Subtest - below average scores ${ }^{d}$ & 8 & 14.5 \\
\hline Symbol Search Subtest - below average scores ${ }^{d}$ & 12 & 23.5 \\
\hline
\end{tabular}

PKU, phenylketonuria; Phe, phenylalanine; WISC, Wechsler Intelligence Scale for Children; WAIS, Wechsler Adult Intelligence Scale

${ }^{a}$ Diagnostic level defined as highest Phe level prior to initiation of dietary therapy

${ }^{\mathrm{b}}$ Index of Dietary Control defined as mean 12-month median Phe level for each patient during the specified age group

${ }^{\mathrm{c}}$ Classified as performing 1 standard deviation below the normative sample on the WISC-III, WISC-IV, or WAIS-III for each patient (scoring $<85$ ), ${ }^{\mathrm{d}}$ (scoring $<7$ )

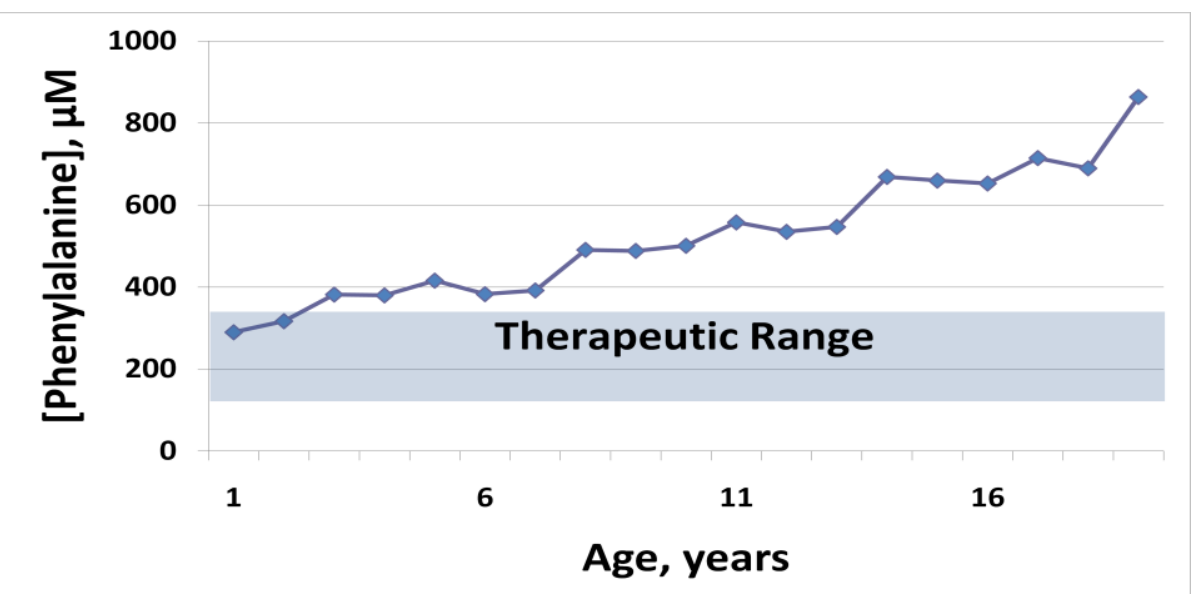

Figure 3-1 Index of Dietary Control, defined as the mean 12-month median of Phe levels, for all patients per year of life (raw data). Therapeutic Range (120-360 $\mu \mathrm{mol} / \mathrm{L})$ defined as the recommended concentration of blood Phe to prevent neurologic decline. 
Diagnostic Phe, days of life at which diet therapy was initiated, concurrent Phe, and mean SD Phe during all age groups were not associated with any measure of intelligence using Pearson product moment correlations (Table 3-3). Perceptual reasoning was significantly correlated with IDC during 0-5 years, 6-10 years, and lifetime but not $>10$ years. Analysis of variance (ANOVA) revealed a significant difference in mean perceptual reasoning scores among those with Phe greater than treatment range ( $>360 \mu \mathrm{mol} / \mathrm{L}$ ) at the time of testing (within 10 days) compared to those within treatment range $(p=0.020)$.

Table 3-3 Pearson product moment correlations between neuropsychological tests and treatment variables

\begin{tabular}{|c|c|c|c|}
\hline Variables & $\begin{array}{r}\text { Verbal } \\
\text { Comprehension }^{\mathrm{c}} \\
\end{array}$ & $\begin{array}{r}\text { Perceptual } \\
\text { Reasoning }{ }^{\mathrm{d}}\end{array}$ & $\begin{array}{r}\text { Processing } \\
\text { Speed }^{\mathrm{e}} \\
\end{array}$ \\
\hline Diagnostic Phe & $.001(.997)$ & $-.003(.983)$ & $-.219(.126)$ \\
\hline Initiation of diet therapy (days of life) & $-.122(.395)$ & $-.156(.275)$ & $-.072(.631)$ \\
\hline \multicolumn{4}{|l|}{ Index of Dietary Control ${ }^{a}$} \\
\hline Lifetime & $-.128(.352)$ & $-.301(.026)$ & $-.108(.451)$ \\
\hline Age $0-5$ years & $-.141(.303)$ & $-.280(.038)$ & $-.025(.863)$ \\
\hline Age 6-10 years & $-.174(.208)$ & $-.370(.006)$ & $-.060(.680)$ \\
\hline Age $>10$ years & $.058(.756)$ & $-.297(.105)$ & $.027(.892)$ \\
\hline Concurrent Phe within 10 days of testing & $-.025(.885)$ & $-.266(.111)$ & $-.205(.246)$ \\
\hline \multicolumn{4}{|l|}{ Mean SD of blood Phe ${ }^{b}$} \\
\hline Lifetime & $-.078(.569)$ & $-.089(.517)$ & $-.071(.619)$ \\
\hline Age $0-5$ years & $-0.41(.766)$ & $.010(.943)$ & $-.060(.674)$ \\
\hline Age $6-10$ years & $-.111(.426)$ & $-.092(.506)$ & $-.092(.527)$ \\
\hline Age $>10$ years & $.121(.524)$ & $-.224(.233)$ & $.016(.936)$ \\
\hline $\begin{array}{l}\text { Phe, phenylalanine; SD, standard deviatio } \\
{ }^{a} \text { Index of Dietary Control defined as mea } \\
\text { specified time frame } \\
{ }^{b} \text { Mean standard deviation of blood Phe d } \\
\text { age group } \\
{ }^{c} \text { Verbal comprehension derived from mea } \\
\text { three cognitive tests: WISC-III, WISC-IV } \\
{ }^{d} \text { Perceptual reasoning derived from mean } \\
\text { cognitive tests: WISC-III, WISC-IV, or V } \\
{ }^{\mathrm{e}} \text { Processing speed derived from mean cor } \\
\text { cognitive tests: WISC-III, WISC-IV, or V }\end{array}$ & $\begin{array}{l}\text { h median Phe levels } \\
\text { nean 12-month SD f } \\
\text { d scores of the Verb } \\
\text {-III for each patient } \\
\text { scores of the Block } \\
\text { r each patient } \\
\text { res of the Symbol Se } \\
\text { r each patient }\end{array}$ & $\begin{array}{l}\text { each patient } \\
\text { Comprehensior } \\
\text { sign subtest in } \\
\text { h subtest in or }\end{array}$ & $\begin{array}{l}\text { g the } \\
\text { the specified } \\
\text { dex in one of } \\
\text { of three } \\
\text { f three }\end{array}$ \\
\hline
\end{tabular}


Bivariate regression analysis revealed no appreciable association between IDC during all developmental periods including lifetime and verbal comprehension scores (Figure 3-2). Interestingly, when WAIS-III scores were removed from the regression analysis leaving only the Wechsler Intelligence Scale for Children, IDC during 0-5 years, 6-10 years, and lifetime significantly predicted verbal comprehension scores

(Figure 3-3).

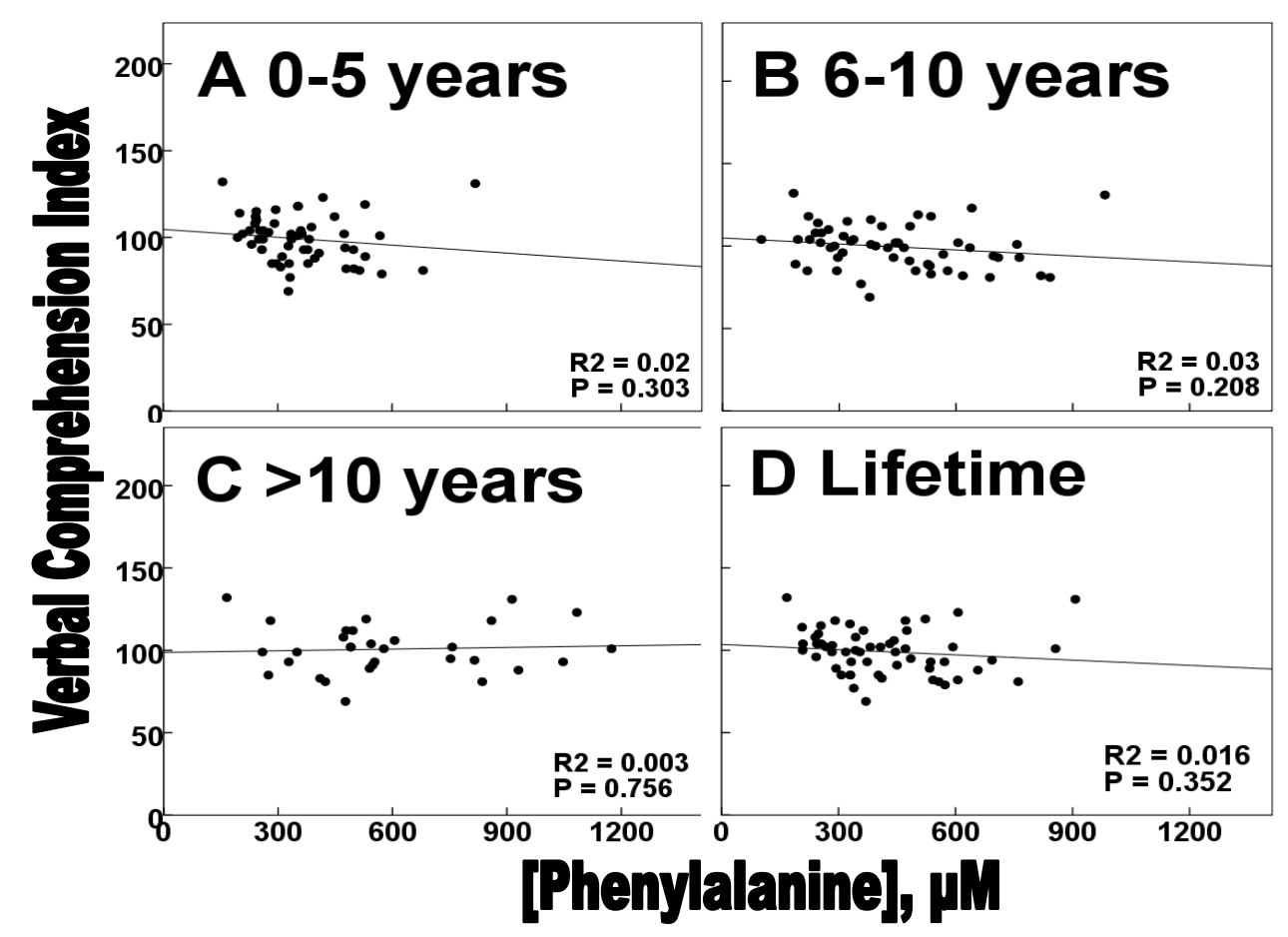

Figure 3-2 Bivariate regression analysis: association between Verbal Comprehension Index (VCI) scores and Index of Dietary Control, defined as the mean 12-month median of Phe levels for each patient during the specified time frame. VCI scores were compiled from three different neuropsychological tests (Wechsler Intelligence Scale for Children III and IV and Wechsler Adult Intelligence Scale III). P values $<0.05$ were considered significant. 


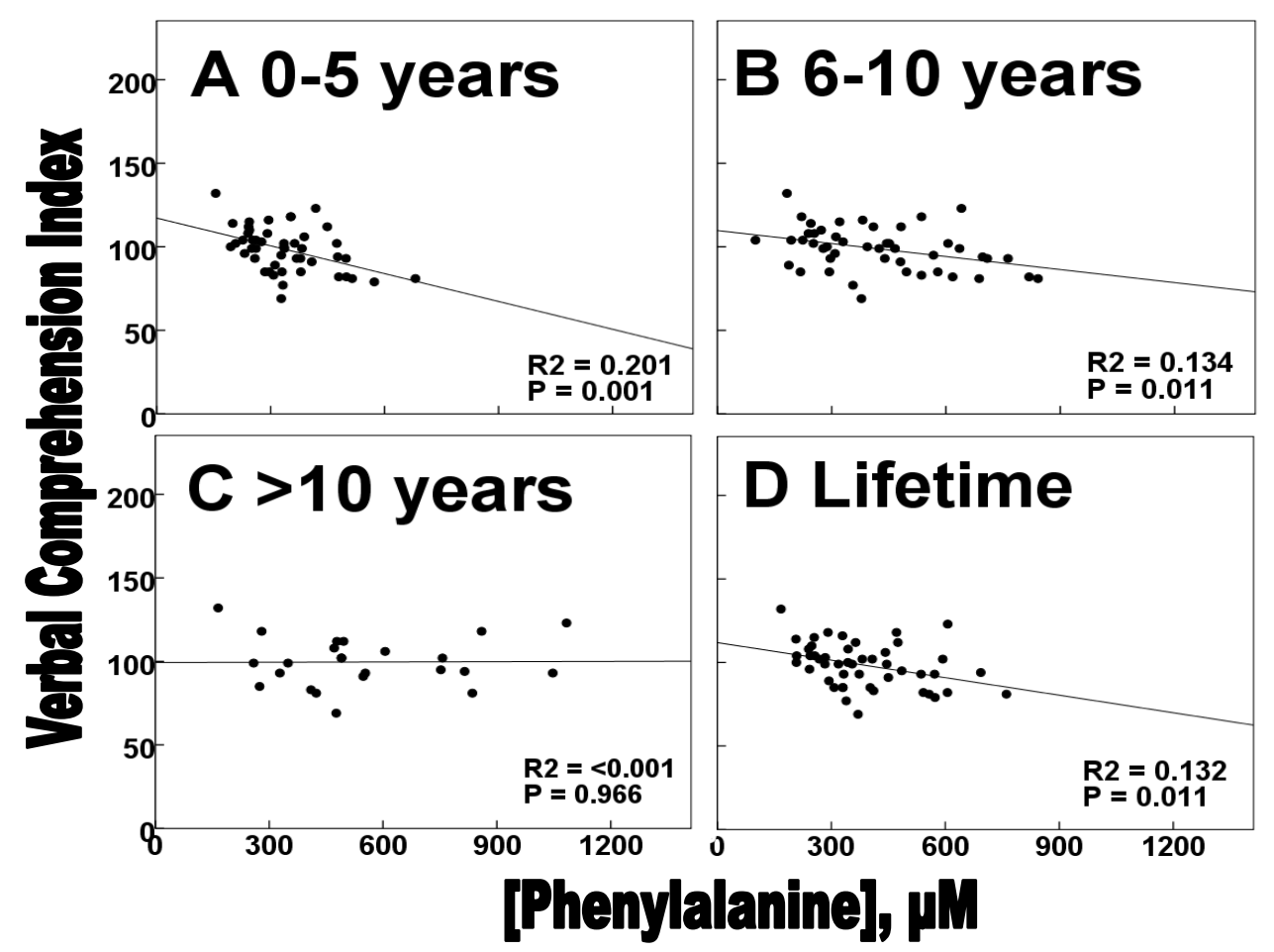

Figure 3-3 Bivariate regression analysis: association between Verbal Comprehension Index (VCI) scores (excluding the Wechsler Adult Intelligence Scale scores) and Index of Dietary Control, defined as the mean 12-month median of Phe levels for each patient during the specified time frame. VCI scores were compiled from two different neuropsychological tests (Wechsler Intelligence Scale for Children III and IV). P values $<0.05$ were considered significant.

Bivariate regression analysis of IDC during 0-5 years, 6-10 years, and lifetime significantly predicted the variance in perceptual reasoning scores (Figure 3-4). A multivariate regression model including IDC and mean number of Phe samples for the 610 year age group accounted for $16.3 \%$ of variance in perceptual reasoning scores $(\mathrm{F}(2,51)=4.981, \mathrm{p}=0.011)$. The IDC regression coefficient for 6-10 years was nonsignificant after controlling for number of blood Phe samples $(\mathrm{p}=0.082)$. The model including mean SD of blood Phe (6-10 years) and number of samples accounted for $11.5 \%$ of the variance in Block Design scores $(F(2,51)=3.316, p=0.044)$. However, the 
significance was attributed to frequency of sampling $(p=0.017)$ rather than mean SD of blood Phe $(\mathrm{p}=0.667)$.

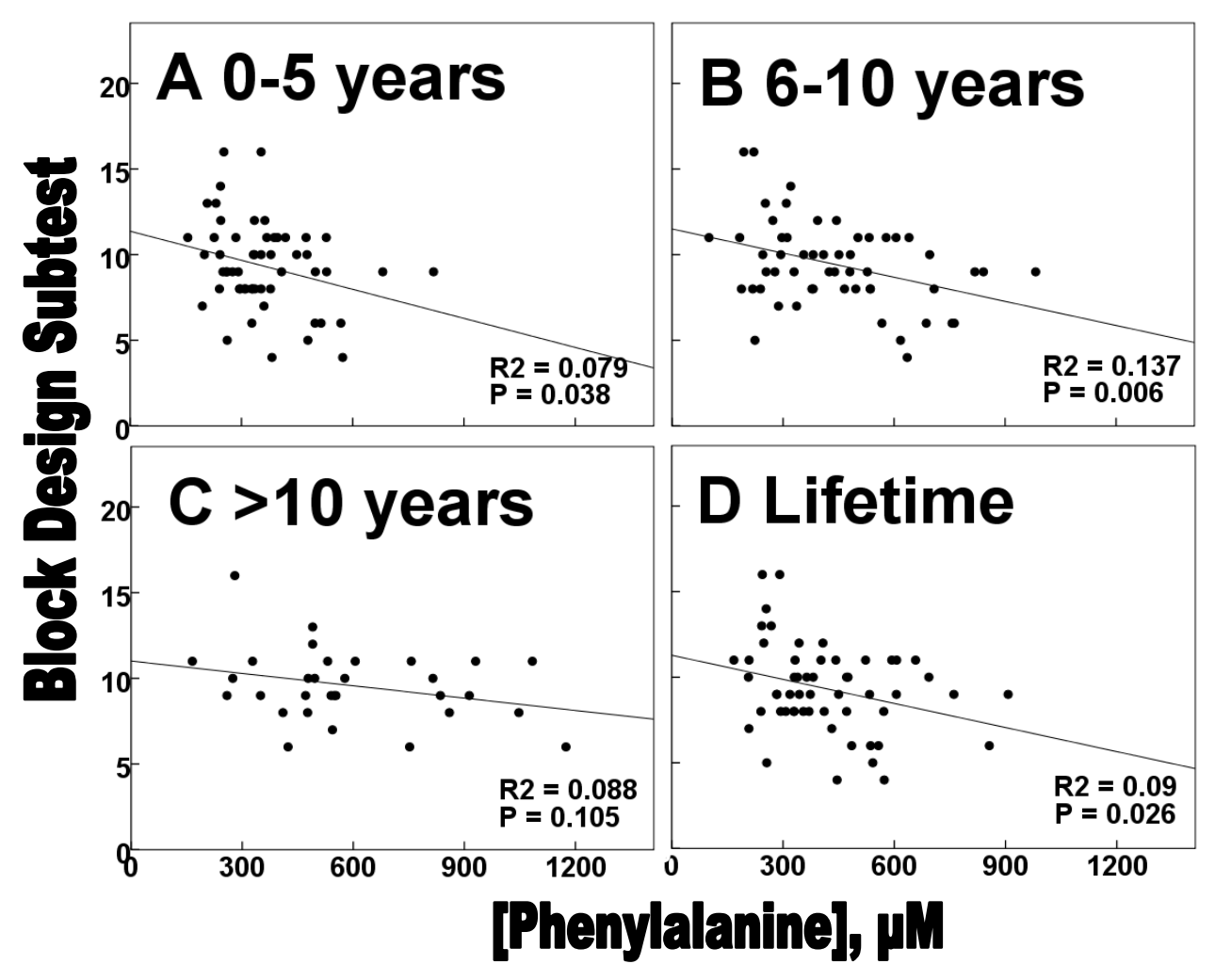

Figure 3-4 Bivariate regression analysis: association between Block Design Subtest scores measuring perceptual reasoning skills and Index of Dietary Control, defined as the mean 12-month median of Phe levels for each patient during the specified time frame. Block Design scores were compiled from three different neuropsychological tests (Wechsler Intelligence Scale for Children III and IV and Wechsler Adult Intelligence Scale III). P values $<0.05$ were considered significant.

Multivariate linear regression (Table 3-4) determined that every $100 \mu \mathrm{mol} / \mathrm{L}$ increase in IDC measured throughout the lifespan was associated with a 0.4-point decrease in perceptual reasoning scores $(\mathrm{p}=0.111)$. IDC from $0-5$ years was associated with a 0.5-point decrease in Block Design scores for every $100 \mu \mathrm{mol} / \mathrm{L}$ increase in blood Phe $(p=0.067)$, though data was nonsignificant. Processing speed, measured with the 
Symbol Search subtest, was not associated with IDC or mean SD Phe for any age group using bivariate and multivariate regression models (Figure 3-5).

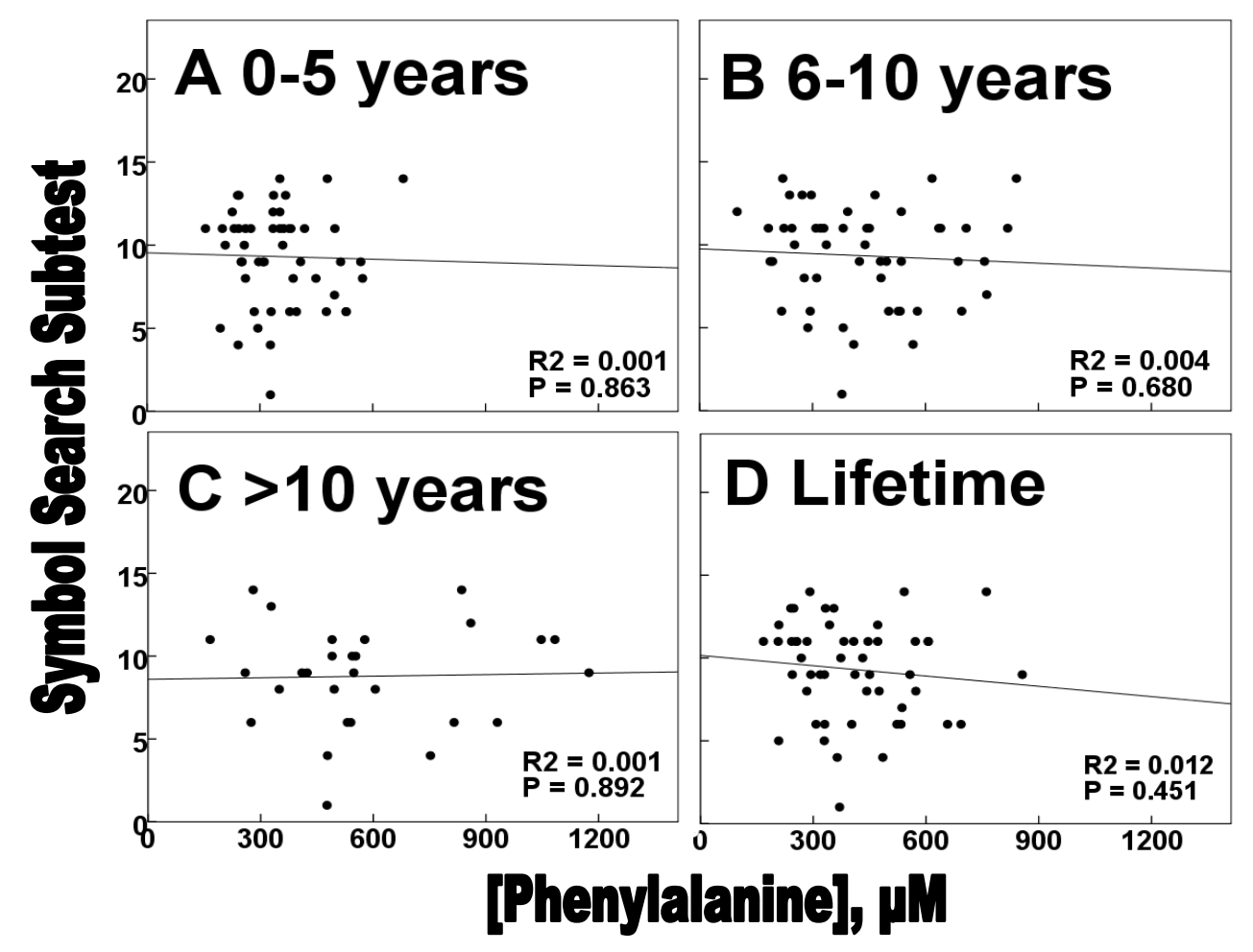

Figure 3-5 Bivariate regression analysis: association between Symbol Search Subtest scores measuring processing speed and Index of Dietary Control, defined as the mean 12month median of Phe levels for each patient during the specified time frame. Symbol Search scores were compiled from three different neuropsychological tests (Wechsler Intelligence Scale for Children III and IV and Wechsler Adult Intelligence Scale III). P values $<0.05$ were considered significant.

While there was no significant correlation between diagnostic Phe and IDC or cognitive scores, diagnostic Phe had a significant positive correlation with the variation of Phe levels during ages $0-5$ years $(r=0.547, p=0.000), 6-10$ years $(r=0.475, p=$ $<0.001)$, and lifetime $(\mathrm{r}=0.537, \mathrm{p}=0.000)$. The IDC for all developmental periods were significantly correlated to SD blood Phe levels ( $\mathrm{p}<0.01$ for all). 
Table 3-4 Multivariate Regression: association between Index of Dietary Control and mean standard deviation of Phe and measures of intelligence

\begin{tabular}{|c|c|c|c|c|c|c|}
\hline Dependent Variables & Independent Variables & $\%$ Variance & $\mathrm{F}$ & $\mathrm{P}$ & $\mathrm{RC}$ & $\mathrm{P}$ \\
\hline \multicolumn{7}{|l|}{ Verbal Comprehension } \\
\hline & IDC Lifetime & 6.4 & 1.769 & .181 & -.003 & .799 \\
\hline & IDC $0-5$ yrs & .7 .1 & 1.998 & .146 & -.011 & .455 \\
\hline & IDC 6-10 yrs & 9.1 & 2.548 & .088 & -.001 & .897 \\
\hline & IDC $>10 \mathrm{yrs}$ & 1.0 & .141 & .869 & .002 & .830 \\
\hline & Mean SD Phe Lifetime & 6.7 & 1.855 & .167 & -.014 & .636 \\
\hline & Mean SD 0-5 yrs & 7.0 & 1.962 & .151 & -.019 & .482 \\
\hline & Mean SD 6-10 yrs & 9.7 & 2.732 & .075 & -.017 & .556 \\
\hline & Mean SD >10 yrs & 5.2 & .739 & .487 & .027 & .441 \\
\hline \multicolumn{7}{|l|}{ Perceptual Reasoning } \\
\hline & IDC Lifetime & 12.1 & 3.566 & .035 & -.004 & .111 \\
\hline & IDC $0-5 \mathrm{yrs}$ & 11.4 & 3.340 & .043 & -.005 & .067 \\
\hline & IDC 6-10 yrs & 16.3 & 4.981 & .011 & -.003 & .082 \\
\hline & IDC $>10 \mathrm{yrs}$ & 8.9 & 1.364 & .272 & -.002 & .125 \\
\hline & Mean SD Phe Lifetime & 8.2 & 2.309 & .109 & -.003 & .585 \\
\hline & Mean SD 0-5 yrs & 5.6 & 1.535 & .225 & -.002 & .770 \\
\hline & Mean SD 6-10 yrs & 11.5 & 3.316 & .044 & -.002 & .667 \\
\hline & Mean SD >10 yrs & 6.2 & .890 & .422 & -.006 & .214 \\
\hline \multicolumn{7}{|l|}{ Processing Speed } \\
\hline & IDC Lifetime & 2.1 & .522 & .597 & -.001 & .633 \\
\hline & IDC $0-5$ yrs & 0.1 & .024 & .977 & -.001 & .853 \\
\hline & IDC 6-10 yrs & 0.9 & .220 & .803 & .000 & .933 \\
\hline & IDC $>10 \mathrm{yrs}$ & 0.1 & .010 & .990 & .000 & .901 \\
\hline & Mean SD Phe Lifetime & 2.1 & .524 & .596 & -.003 & .630 \\
\hline & Mean SD 0-5 yrs & 0.4 & .088 & .916 & -.003 & .687 \\
\hline & Mean SD 6-10 yrs & 1.6 & .392 & .678 & -.004 & .558 \\
\hline & Mean SD >10 yrs & 0.9 & .110 & .896 & .000 & .648 \\
\hline
\end{tabular}

Phe, phenylalanine; SD, standard deviation; IDC, index of dietary control; RC, regression coefficient; $\mathrm{p}$, significance

Covariates of the regression model include concurrent Phe (within 10 days of testing), SD blood Phe, mean number of Phe samples.

${ }^{a}$ IDC defined as mean 12-month median for each patient during the specified time frame

${ }^{\mathrm{b}}$ Mean standard deviation of blood Phe defined as mean 12-month SD for each patient during the specified age group

${ }^{c}$ Verbal comprehension derived from mean compiled scores of the Verbal Comprehension Index in one of three cognitive tests: WISC-III, WISC-IV, or WAIS-III for each patient

${ }^{\mathrm{d}}$ Perceptual reasoning derived from mean compiled scores of the Block Design subtest in one of three cognitive tests: WISC-III, WISC-IV, or WAIS-III for each patient

${ }^{\mathrm{e}}$ Processing speed derived from mean compiled scores of the Symbol Search subtest in one of three cognitive tests: WISC-III, WISC-IV, or WAIS-III for each patient 
Lifetime mean number of blood Phe samples and samples from 6-10 years significantly predicted the likelihood of maintaining blood Phe within the treatment range of 120-360 $\mu \mathrm{mol} / \mathrm{L}$ after controlling for age. Every additional blood Phe sample per year of life predicted a 1.2 percent decreased risk of IDC above treatment range $(p=0.034)$, and every additional sample per year from ages 6-10 years predicted a 32.3 percent decreased risk of blood Phe over $360 \mu \mathrm{mol} / \mathrm{L}(\mathrm{p}=0.001)$. For every additional year of life from birth to 5 years, participants had a 25 percent increased risk of IDC above treatment range $(\mathrm{p}=0.001)$. This risk was increased 14.6 percent from 6 to 10 years of age $(p=0.039)$. Mean number of Phe samples did not significantly predict the probability of mean SD blood Phe within one SD of the IDC per age group (Table 3-5).

Table 3-5 Logistic Regression: number of blood Phe samples predicting likelihood of maintaining blood Phe within treatment range of (120-360 $\mu \mathrm{mol} / \mathrm{L})$ and stability of Phe within one SD per age group

\begin{tabular}{|c|c|c|c|c|c|c|c|c|}
\hline & \multicolumn{4}{|c|}{ Number of Blood Phe Samples } & \multicolumn{4}{|c|}{ Age } \\
\hline & Odds & & $95 \% \mathrm{CI}$ & $95 \% \mathrm{CI}$ & Odds & & $95 \% \mathrm{CI}$ & $95 \% \mathrm{CI}$ \\
\hline Phe per Age Group ${ }^{a}$ & Ratio & $\mathrm{P}$ & Lower & Upper & Ratio & $\mathrm{P}$ & Lower & Upper \\
\hline Lifetime & .988 & .034 & .731 & 1.021 & 1.462 & $<.001$ & 1.110 & 1.461 \\
\hline $0-5$ years & .925 & .225 & .817 & 1.049 & 1.250 & .001 & 1.098 & 1.423 \\
\hline $6-10$ years & .677 & .001 & .534 & .859 & 1.146 & .039 & 1.007 & 1.304 \\
\hline$>10$ years & .959 & .714 & .766 & 1.201 & 1.248 & .054 & .995 & 1.656 \\
\hline \multicolumn{9}{|l|}{ Phe SD per Age Group } \\
\hline Lifetime $^{\mathrm{b}}$ & .982 & .188 & .899 & 1.163 & 1.372 & .013 & 1.093 & 1.382 \\
\hline $0-5$ years $^{c}$ & 1.066 & .166 & .931 & 1.172 & 1.217 & .052 & 1.061 & 1.430 \\
\hline $6-10$ years $^{d}$ & .687 & .136 & .886 & 1.272 & 1.138 & .148 & 1.048 & 1.294 \\
\hline$>10$ years ${ }^{e}$ & 1.078 & .543 & .746 & 1.124 & 1.199 & .110 & 1.005 & 1.472 \\
\hline
\end{tabular}

Phe, phenylalanine; SD, standard deviation; $\mathrm{p}$, significance; $\mathrm{CI}$, confidence interval

Age was included as a covariate in the regression model

${ }^{\text {a }}$ Phe per age group defined as mean 12-month median for each patient during the specified time frame

1 SD defined as: Lifetime $\pm 165^{\mathrm{b}} ; 0-5$ years $\pm 127^{\mathrm{c}} ; 6-10$ years $\pm 196^{\mathrm{d}} ;>10$ years $\pm 258^{\mathrm{e}}$ 
DISCUSSION

The present study demonstrates an important link between blood Phe levels during the 6-10 year developmental period and perceptual reasoning skills, specifically visual-spatial reasoning and visual constructional ability measured by the Block Design subtest. IDC had a significant negative correlation with Block Design scores though no association was found with mean SD blood Phe. IDC and number of Phe samples accounted for 16.3 percent of the variance in perceptual reasoning, but using multivariate regression, IDC was nonsignificant after controlling for number of blood Phe samples.

Despite adequate treatment, patients with PKU demonstrate impairments that worsen over time in arithmetic, reading comprehension, basic spelling, and perceptual skill (Stemerdink et al. 2000). In a previous study, teachers reported that 33 percent of students exhibited more problems in mathematics and spelling than other students (Weglage et al. 1993). Berry et al. (1979) demonstrated those with early treated PKU scored significantly lower on measures of mathematical skills compared to healthy controls $(\mathrm{p}<0.05)$. Visual-spatial and perceptual deficits negatively impact these skills, which may be misinterpreted as lower intelligence (Chang et al. 2000; Channon et al. 2009; Antshel 2010; Janzen and Nguyen 2010). Data from the present study demonstrates blood Phe levels $>360 \mu \mathrm{mol} / \mathrm{L}$ within 10 days of cognitive testing in the 610 year age group produced significantly different results from those with blood Phe $<360 \mu \mathrm{mol} / \mathrm{L}$. Therefore, maintaining IDC $<360 \mu \mathrm{mol} / \mathrm{L}$ during ages $6-10$ years may reduce the risk of developing academic impairments related to perceptual reasoning.

The PKU Adult Collaborative Study (Brumm et al. 2004) revealed a negative association between language functioning skills and lifetime blood Phe levels and a 
positive correlation with number of years on dietary therapy. Koch et al. (1999) also reported higher language scores for those who continued a Phe-restricted diet beyond 12 years of age compared to those that discontinued diet therapy at 12 years. Additionally, measures of verbal fluency, expressive naming, and receptive vocabulary were significantly lower for those with concurrent Phe $>1000 \mu \mathrm{mol} / \mathrm{L}$ compared to patients with Phe $<1000 \mu \mathrm{mol} / \mathrm{L}$ (Brumm et al. 2004). The present study found no significant associations between treatment variables and verbal comprehension scores. Frequency of blood Phe monitoring during the 6-10 age group predicted a 1.104-point increase in VCI scores for every additional blood Phe sample per year, though data was nonsignificant $(\mathrm{p}=0.071)$

Speed of processing measured by the Symbol Search subtest was not associated with IDC or mean SD blood Phe during any developmental period. Brumm et al. (2004) found no significant association between current Phe levels and processing speed in adults as measured by the Trail-Making Test Part A. However, processing speed was significantly correlated with abnormal MRI scans, which are associated with elevated blood Phe (Solan 1987; Chang et al. 2000; Brumm et al. 2004; White et al. 2010). While measures of processing speed were not sensitive to concentration or variability of blood Phe in the present study, deficits are commonly featured in early and continuously treated patients with PKU when compared to healthy controls (Cleary et al. 1995; Kaufman and Lichtenberger 1999; Channon et al. 2005; Janzen and Nguyen 2010).

Lezak (1995) reported IQ tests are typically insensitive to subtle cognitive deficits. The Block Design subtest appeared to be more sensitive to IDC and mean SD blood Phe levels than the VCI or the Symbol Search subtest. Exclusion of scores from 
the WAIS-III altered results from analyses predicting VCI. After excluding the WAIS-III scores from analysis, the IDC from 0-5 years significantly predicted a 5.1-point decrease in VCI scores for every $100 \mu \mathrm{mol} / \mathrm{L}$ increase in blood Phe $(p=0.002)$. Analysis of WAIS-III scores only was not possible due to small sample size. This suggests the Comprehension subtest included in the WISC-III and -IV was more sensitive to blood Phe levels than the Information subtest in the WAIS-III.

Classification of PKU severity based on diagnostic Phe was not related to IDC, but it was significantly correlated to mean SD Phe levels. This suggests that the severity of the PKU phenotype may not predict the likelihood of maintaining blood Phe within treatment range (Moyle et al. 2007; Olsson et al. 2007), but may reflect an increased risk of high variability in blood Phe (Moyle et al. 2007). In addition, IDC was positively correlated with SD Phe, which is in agreement with previous studies suggesting higher blood Phe concentrations lead to greater variability in Phe levels (Anastasoaie et al. 2008; Vilaseca et al. 2010).

Frequency of blood Phe monitoring significantly predicted the likelihood of maintaining IDC within treatment range between 6-10 years and throughout the lifespan. Vilaseca et al. (2010) reported a significant difference $(\mathrm{p}=<0.001)$ in IDC between those with good (proportion of recommended samples was $>90 \%$ ), intermediate $(>75 \%)$, and poor $(<75 \%)$ frequency of testing. It should be noted that recommended frequency of testing is related to metabolic control. Patients with blood Phe levels consistently above treatment range are recommended to take more frequent levels compared to patients with good metabolic control. Mean number of samples per year of life were below the minimum recommended frequency (monthly levels) in those 6-10 years, $>10$ 
years, and lifetime. Therefore, appropriate recommendations for frequency of blood Phe samples at different ages cannot be inferred from this data.

\section{LIMITATIONS}

There are several limitations that may impact the interpretation of results from the present study. Participants in this study were not selected randomly but were chosen from patients receiving treatment at the Utah Metabolic Clinic. Therefore, results may not reflect the characteristics of the population. Intelligence was measured with selected subtests of three different neuropsychological tests due to structural differences between measures rather than full scale IQ. Eliminating subtests from statistical analysis may not portray overall intelligence or compare to previous research measuring full scale IQ. There is also an increased risk of type 1 error due to small sample size, large number of exposure variables and multiple comparisons.

\section{CONCLUSION}

In summary, our findings suggest an association between the quality of metabolic control during specific developmental periods and measures of intelligence. Appropriate blood Phe control during ages 0-5 years and 6-10 years may have a greater influence on perceptual reasoning abilities than other periods of life. The importance of regular monitoring of blood Phe levels should be emphasized especially in those aged 6-10 years, as increased blood Phe monitoring decreases the probability that IDC will exceed the upper limit of the therapeutic range $(360 \mu \mathrm{mol} / \mathrm{L})$. Concentration and variability of blood may impact specific areas of verbal comprehension abilities for those $0-5$ years of age. It 
does not lend support to the hypothesis that variability in blood Phe may be a useful indicator of intelligence later in life.

\section{REFERENCES}

Anastasoaie V, Kurzius L, Forbes P, Waisbren S (2008) Stability of blood phenylalanine levels and IQ in children with phenylketonuria. Mol Genet Metab 95:17-20.

Anderson PJ, Leuzzi V (2010) White matter pathology in phenylketonuria. Mol Genet Metab 99: S3-S9.

Anderson PJ, Wood SJ, Francis DE, Coleman L, Anderson V, Boneh A (2007) Are neuropsychological impairments in children with early-treated phenylketonuria related to white matter abnormalities or elevated phenylalanine levels? Developmental Neuropsychology 32: 645-668.

Antshel KM (2010) ADHD, learning, and academic performance in phenylketonuria. Mol Genet Metab 99: S52-S58.

Antshel KM, Waisbren SE (2003) Timing is everything: executive functions in children exposed to elevated levels of phenylalanine. Neuropsychology 17: 458-468.

Azen C, Koch R, Friedman E, Wenz E, Fishler K (1996) Summary of findings from the United States Collaborative Study of children treated for phenylketonuria. Eur J Pediatr 155: S29-S32.

Berry HK, O’Grady DJ, Perlmutter LJ, Bofinger MK (1979) Intellectual development and academic achievement of children early treated for phenylketonuria. Dev Med Child Neurol 21: 311-320.

Brumm VL, Azen C, Moats RA Stern AM, Broomand C, Nelson MD, Koch R (2004) Neuropsychological outcome of subjects participating in the PKU Adult Collaborative Study: A preliminary review. J Inherit Metab Dis 27: 549-566.

Burgard J (2000) Development of intelligence in early treated phenylketonuria. Eur J Pediatr 159: S74-S79.

Burgard P, Bremer HJ, Buhrdel P, Clemens PC, Monch E, Przyrembel H, Trefz FK, Ullrich K (1997) Rationale for the German recommendations for phenylalanine level control in phenylketonuria. Eur J Pediatr 158: 46-54.

Burgard P, Luo Xiaoping, Hoffmann GF (2009) Phenylketonuria. In: Sarafoglou K, Hoffman GF, Roth KS, eds. Pediatric Endocrinology and Inborn Errors of Metabolism. New York: McGraw Hill Companies, pp 163-168. 
Chang P, Gray RM, O’Brien LL (2000) Patterns of academic achievement among patients treated early with phenylketonuria. Eur J Pediatr 159: S96-S99.

Channon S, Goodman G, Zlotowitz S, Mockler C, Lee PJ (2009) Effects of dietary management of phenylketonuria on long-term cognitive outcome. Arch Dis Child 2: 213-218.

Channon S, Mockler C, Lee P (2005) Executive functioning and speed of processing in phenylketonuria. Neuropsychology 19: 679-686.

Cleary MA, Walter JH, Wrath JE, Jenkins JPR (1995) Magnetic resonance imaging in phenylketonuria: Reversal of cerebral white matter change. J Pediatr 127: 251-255.

de Sonneville LMJ, Huijbregts SCJ, van Spronsen FJ, Verkerk PH, Sergeant JA, Licht R (2010) Event-related potential correlates of selective processing in early- and continuously-treated children with phenylketonuria: Effects of concurrent phenylalanine level and dietary control. Mol Genet Metab 99: S10-S17.

Dyer CA (2000) Comments on the Neuropathology of Phenylketonuria. Eur J Pediatr 159 (Suppl 2): S107-S108.

Feillet F, MacDonald A, Hartung D, Burton B (2010) Outcomes beyond phenylalanine: An international perspective. Mol Genet Metab 99: S79-S85.

Feldmann R, Denecke J, Pietsch M, Grenzebach M, Weglage J (2002) Phenylketonuria: no specific frontal lobe-dependent neuropsychological deficits in early-treated patients in comparison with diabetics. Pediatr Res 51: 761-765.

Fishler K, Azen C, Henderson R, Friedman EG, Koch R (1987) Psychoeducational findings among children treated for phenylketonuria. Am J Ment Defic 92: 65-73.

Flanagan DP, Kaufman AS (2009) Essentials of WISC-IV Assessment. Hoboken, NJ:Wiley.

Gassio R, Artuch R, Vilaseca MA, Fuste E, Boix C, Sans A, Campistol J (2005) Cognitive functions in classic phenylketonuria and mild hyperphenylalaninaemia: experience in a pediatric population. Developmental Medicine and Child Neurol 47: 443448.

Gassio R, Fuste E, Lopez-Sala A, Artuch R, Vilaseca MA, Campistol J (2005) School performance in early and continuously treated phenylketonuria. Pediatr Neurol 33: 267271.

Gentile JK, Ten Hoedt AE, Bosch AM (2010) Psychosocial aspects of PKU: hidden disabilities - a review. Mol Genet Metab 99: S64-S67. 
Gregory CO, Yu C, Singh RH (2007) Blood phenylalanine monitoring for dietary compliance among patients with phenylketonuria: comparison of methods. Genetics in Medicine 9: 761-765.

Janzen D, Nguyen M (2010) Beyond executive function: non-executive cognitive abilities in individuals with PKU. Mol Genet Metab 99: S47-S51.

Kaufman AS, Lichtenberger EO (1999) Essentials of WAIS-III Assessment. New York: JohnWiley \& Sons, Inc.

Koch R, Moseley K, Ning J, Romstad A, Guldberg P, Guttler F (1999) Long-term beneficial effects of the phenylalanine-restricted diet in late-diagnosed individuals with phenylketonuria. Mol Genet Metab 67: 148-155.

Leuzzi V, Pansini M, Sechi E (2004) Executive impairment in early-treated PKU subjects with normal mental development. J Inherit Metab Dis 27: 115-125.

Lezak M (1995) Neuropsychological assessment, 3rd ed. New York: Oxford University Press.

Moyle JJ, Fox AM, Arthur M, Byneveldt M, Burnett JR (2007) Meta-analysis of neuropsychological symptoms of adolescents and adults with PKU. Neuropsychol Rev 17: 91-101.

Moyle JJ, Fox AM, Bynevelt M, Arthur M, Burnett JR (2007) A neuropsychological profile of off-diet adults with phenylketonuria. J Clinical and Experimental Neuropsychology 29: 436-441.

NIH (2000) Phenylketonuria (PKU): screening and management. NIH Consensus Statement 17: 1-33.

Olsson GM, Montgomery SM, Alm J (2007) Family conditions and dietary control in phenylketonuria. J Inherit Metab Dis 30: 708-715.

Rice D, Barone S (2000) Critical Periods of Vulnerability for the Developing Nervous System: Evidence from Humans and Animal Models. Environ Health Perspect 108: S511-S533.

Smith J, Beasley M (1989) Intelligence and behavior in children with early treated phenylketonuria. A report from the MRC/DHSS phenylketonuria register. Eur J Clin Nutr 43: S1-S5.

Solan HA (1987) The effects of visual-spatial and verbal skills on written and mental arithmetic. J Am Optom Assoc 58: 88-94. 
Stemerdink BA, Kalverboer AF, Van der Meere JJ (2000) Behavior and school achievement in patients with early and continuously treated phenylketonuria. J Inherit Metab Dis 23: 548-562.

VanZutphen KH, Packman W, Sporri L (2007) Executive functioning in children and adolescents with phenylketonuria. Clin Genet 72: 13-18.

Vilaseca MA, Lambruschini N, Gomez-Lopez L (2010) Quality of dietary control in phenylketonuric patients and its relationship with general intelligence. Nutr Hosp 25: 6066.

Waisbren S, Noel K, Fahrbach K, Cella C, Frame D, Dorenbaum A, Levy H (2007) Phenylalanine blood levels and clinical outcomes in phenylketonuria: a systematic literature review and meta-analysis. Mol Genet Metab 92: 63-70.

Walter JH, White FJ, MacDonald A (2002) How practical are recommendations for dietary control in phenylketonuria? Lancet 360: 55-57.

Wappner R, Cho S, Kronmal RA, Schuett V, Seashore MR (1999) Management of phenylketonuria for optimal outcome: a review of guidelines for phenylketonuria management and a report of surveys of parents, patients, and clinic directors. Pediatrics 104:e68.

Wechsler D (2003) WISC - IV Australian Administration and Scoring Manual. Harcourt Assessment.

Weglage J, Funders B, Wilken B, Schubert D, Schmidt E, Burgard P, Ullrich K (1992) Psychological and social findings in adolescents with phenylketonuria. Eur J Pediatr 151: $522-525$.

Weglage J, Funders B, Wilken B, Schubert D, Ullrich K (1993) School performance and intellectual outcome in adolescents with phenylketonuria. Acta Paediatr 82: 582-586.

Wendel U, Ullrich K, Schimdt H, Batzler U (1990) Six-year follow up of phenylalanine intakes and plasma phenylalanine concentrations. Eur J Pediatr 149 (Suppl 1): S13-S16.

White DA, Tabor Connor L, Nardos B (2010) Age-related decline in the microstructural integrity of white matter in children with early- and continuously-treated PKU: a DTI study of corpus callosum. Mol Genet Metab 99: S41-S46.

Williams PE, Weiss LG, Folfhus EL (2003) WISC-IV Technical Manual \#2. The Psychological Corporation. 
CHAPTER 4

\section{CONCLUSIONS AND FUTURE DIRECTIONS}

It is widely accepted that metabolic control during early childhood is related to intelligence later in life. The results from the present study support findings from previous research in this regard. Quality of metabolic control had the most influence on intelligence during the 0-5 year and 6-10 year developmental periods. Concentration and variability in blood Phe in the 0-5 year age group significantly predicted verbal comprehension skills in those less than 18 years, and concentration of blood Phe in the 0 5 year and 6-10 year age groups were related to perceptual reasoning abilities.

Perceptual reasoning was the most notably affected measure of intelligence. It was significantly correlated to both mean of median Phe and concurrent Phe in the 6-10 year age group. It was also associated with the IDC Phe for lifetime levels and from 0-5 years. Impaired perceptual reasoning may negatively impact reading comprehension, mathematics, and spelling (Chang et al. 2000). If perceptual reasoning abilities are impaired as early as 6-10 years, these children may fall behind as they progress through their schooling, which could reduce their long-term intelligence. Therefore, children with PKU should regularly undergo cognitive assessment to identify potential learning disabilities early in life in order to develop an appropriate education plan.

The relationship between Verbal Comprehension Index (VCI) scores and the mean of median and standard deviation (SD) blood Phe in the 0-5 age group could indicate that blood Phe impacts verbal comprehension during childhood, but the effect dissipates as they become adults. It may also be related to the test itself, which measures general knowledge as compared to social knowledge and awareness. Further research is 
needed to explore the impact of blood Phe during early childhood on long-term verbal comprehension skills. Moreover, it would be of worth to prospectively compare individual performance over-time, comparing the highest and the lowest score achieved in VCI with Phe levels at different periods.

Mean number of blood Phe samples per year was significantly different from the 0-5 year age group to the 6-10 year age group. Middle to late childhood is often the age where patients and their caretakers become more relaxed regarding diet restrictions and blood Phe monitoring (Weglage et al. 1992). One possible rationale for this is due to the previous guidelines to discontinue dietary therapy at 5 years of age. This gives the impression that brain development is completed at this age and strict control of blood Phe levels is no longer necessary. Therefore, families may be less likely to overcome common barriers to compliance. Clinicians must reinforce the importance of regular monitoring of blood Phe levels and appropriate dietary control for patients in the 6-10 age group.

In a survey of $32 \mathrm{PKU}$ patients and their primary caretakers residing in Utah, 78 percent reported utilizing blood Phe results to adjust dietary intake (Bilginsoy et al. 2005). The majority of caretakers agreed that blood Phe levels were their primary indicator of how well they were doing. However, several participants also described blood Phe testing as cumbersome and time consuming. A home blood Phe monitoring device has been suggested to improve metabolic control in patients with PKU. Patients universally reported that a home monitoring device would improve the management of the disease and increase adherence to a Phe-restricted diet (Bilginsoy et al. 2005). 
While the University of Utah Metabolic Clinic determines recommended frequency of blood Phe monitoring on an individual basis, mean number of blood Phe samples per year was less than the minimum recommended frequency for all age groups. The impact of the number of blood Phe samples on VCI scores and IDC accentuates its importance in the treatment of PKU. However, optimal frequency of testing cannot be deduced from this data. Further guidance regarding this issue may emerge with the development of a home blood Phe monitoring device.

Previous studies suggest variation in blood Phe may be a stronger indicator of intelligence than blood Phe concentrations in those greater than 10 years (Anastasoaie et al. 2008). The present study does not lend support to this hypothesis, but further research is needed. If blood Phe variation is associated with later intelligence in PKU, the use of medications, such as sapropterin dihydrochloride, may be useful to limit wide fluctuations.

Determining predictors of long-term IQ in early treated patients with PKU is an area of interest. Participants in a survey of early treated adults with PKU expressed anxiety regarding uncertainty about their prognosis, as they are the first generation of early-treated adults with PKU. This uncertainty pertained to length of life and how long participants would retain their mental faculties in addition to the value of optimal blood Phe levels (Frank et al. 2007).

The present study contributes to the debate regarding the impact of concentration and variation of blood Phe during specific developmental periods on intelligence. Overall, our findings suggest early detection and strict adherence to diet and blood Phe monitoring would be beneficial to improve cognitive outcomes in patients with PKU. 


\section{REFERENCES}

Anastasoaie V, Kurzius L, Forbes P, Waisbren S (2008) Stability of blood phenylalanine levels and IQ in children with phenylketonuria. Mol Genet Metab 95: 17-20.

Bilginsoy C, Waitzman N, Leonard CO, Ernst SL (2005) Living with phenylketonuria: perspectives of patients and their families. J Inherit Metab Dis 28: 639-649.

Chang P-N, Gray RM, O’Brien L (2000) Patterns of academic achievements among patients treated early with phenylketonuria. Eur J Pediatr 159: [Suppl 2]: S96-S99.

Frank N, Fitzgerald R, Legge M (2007) Phenylketonuria - the lived experience. NZMJ 120: 2728.

Weglage J, Funders B, Wilken B, Schubert D, Schmidt E, Burgard P, Ullrich K (1992) Psychological and social findings in adolescents with phenylketonuria. Eur J Pediatr 151: 522-5. 
Appendix. Permission to Use Letters 
June 28, 2010

Krista Viau

$50 \mathrm{~N}$ Medical Dr

SOM, Rm 2C412

Salt Lake City, UT 84132

(801) 587-9590

Dear Dr. Nancy Cantor:

I am in the process of preparing my thesis in the Nutrition, Dietetics, and Food Science Department at Utah State University. I hope to complete my degree in the summer of 2010.

I am requesting your permission to include the attached material as shown. I will include acknowledgments to your work as shown (page v) and copyright and reprint rights information in a special appendix. Please advise me of any changes you require.

Please indicate your approval of this request by signing in the space provided, attaching any other form or instruction necessary to confirm permission. If you charge a reprint fee for use of your material, please indicate that as well. If you have any questions, please call me at the number above.

I hope you will be able to reply immediately. If you are not the copyright holder, please forward my request to the appropriate person or institution.

Thank you for your cooperation,

Krista Viau

I hereby give permission to Krista Viau to reprint the following material in her thesis.

Signed

Date 
June 28, 2010

Krista Viau

$50 \mathrm{~N}$ Medical Dr

SOM, Rm 2C412

Salt Lake City, UT 84132

(801) 587-9590

Dear Sharon Ernst:

I am in the process of preparing my thesis in the Nutrition, Dietetics, and Food Science Department at Utah State University. I hope to complete my degree in the summer of 2010.

I am requesting your permission to include the attached material as shown. I will include acknowledgments to your work as shown (page v) and copyright and reprint rights information in a special appendix. Please advise me of any changes you require.

Please indicate your approval of this request by signing in the space provided, attaching any other form or instruction necessary to confirm permission. If you charge a reprint fee for use of your material, please indicate that as well. If you have any questions, please call me at the number above.

I hope you will be able to reply immediately. If you are not the copyright holder, please forward my request to the appropriate person or institution.

Thank you for your cooperation,

Krista Viau

I hereby give permission to Krista Viau to reprint the following material in her thesis.

Signed

Date 
June 28, 2010

Krista Viau

$50 \mathrm{~N}$ Medical Dr

SOM, Rm 2C412

Salt Lake City, UT 84132

(801) 587-9590

Dear Dr. Larissa Furtado:

I am in the process of preparing my thesis in the Nutrition, Dietetics, and Food Science Department at Utah State University. I hope to complete my degree in the summer of 2010.

I am requesting your permission to include the attached material as shown. I will include acknowledgments to your work as shown (page v) and copyright and reprint rights information in a special appendix. Please advise me of any changes you require.

Please indicate your approval of this request by signing in the space provided, attaching any other form or instruction necessary to confirm permission. If you charge a reprint fee for use of your material, please indicate that as well. If you have any questions, please call me at the number above.

I hope you will be able to reply immediately. If you are not the copyright holder, please forward my request to the appropriate person or institution.

Thank you for your cooperation,

Krista Viau

I hereby give permission to Krista Viau to reprint the following material in her thesis.

Signed

Date 
June 28, 2010

Krista Viau

$50 \mathrm{~N}$ Medical Dr

SOM, Rm 2C412

Salt Lake City, UT 84132

(801) 587-9590

Dear Dr. Nicola Longo:

I am in the process of preparing my thesis in the Nutrition, Dietetics, and Food Science Department at Utah State University. I hope to complete my degree in the summer of 2010.

I am requesting your permission to include the attached material as shown. I will include acknowledgments to your work as shown (page v) and copyright and reprint rights information in a special appendix. Please advise me of any changes you require.

Please indicate your approval of this request by signing in the space provided, attaching any other form or instruction necessary to confirm permission. If you charge a reprint fee for use of your material, please indicate that as well. If you have any questions, please call me at the number above.

I hope you will be able to reply immediately. If you are not the copyright holder, please forward my request to the appropriate person or institution.

Thank you for your cooperation,

Krista Viau

I hereby give permission to Krista Viau to reprint the following material in her thesis.

Signed

Date 
